\title{
Intelligent E-Vendor Relationship Management for Enhancing Global B2C E-Commerce Ecosystems
}

\author{
H. Y. Lam, The Hang Seng University of Hong Kong, Hong Kong \\ iD https://orcid.org/0000-0002-5858-1894 \\ Y. P. Tsang, The Hong Kong Polytechnic University, Hong Kong \\ iD https://orcid.org/0000-0002-6128-345X \\ C. H. Wu, The Hang Seng University of Hong Kong, Hong Kong \\ (iD) https://orcid.org/0000-0003-1259-4048 \\ C. Y. Chan, The Hong Kong Polytechnic University, Hong Kong
}

\begin{abstract}
Recently, global e-commerce businesses have been blooming due to the convenience they offer, their product range, and the individualized products and services they offer. To maintain an entire ecosystem, effective platform-vendor relationships should be considered, through which e-commerce platforms can provide collaborative packages to vendors. E-vendor relationship management (eVRM) should then be developed to identify, attract, retain, and develop existing and new vendors so that groups of loyal vendors can be managed. However, eVRM in e-commerce is an area that has received less attention. This paper proposes an adaptive e-vendor relationship-management system (AVRMS) to provide decision-making support for the formulation of vendor management strategies. The contribution of this study is that it addresses the missing link of platform-vendor relationship management in global e-commerce environments, while integrating data-driven approaches and artificial intelligence techniques to generate a new synergy for the facilitation of eVRM.
\end{abstract}

\section{KEYWORDS}

Fuzzy C-Means Clustering, Global E-Commerce, Vendor Relationship Management

\section{INTRODUCTION}

Numerous e-commerce platforms have been developed in quick succession, aimed at global e-commerce environments and designed to enable electronic transactions involving general commodities and day-to-day services. Most of these platforms (and research) has focused on customer relationship management (CRM) in e-commerce, in order to maintain and attract a loyal and active customer base (Mazzarol, 2015; Wang et al., 2016). Effective CRM can identify, attract, retain and develop a loyal and active customer base, promoting engagement through activities on e-commerce platforms, which improve profitability and business reputations in a sustainable manner. Apart from the customer perspective, some e-commerce platforms (particularly those operating global e-commerce businesses) also pay attention to vendor and supplier management in order to create a

\section{DOI: $10.4018 / J G I M .2021050101$}

This article, published as an Open Access article on April 16, 2021 in the gold Open Access journal, Journal of Global Information Management (JGIM) (converted to gold Open Access on January 1, 2021), is distributed under the terms of the Creative Commons Attribution 
trusting and reliable business environment (Hamidi and Moradi, 2017; Kim and Peterson, 2017). The differences between vendors and suppliers in e-commerce are shown in Table 1, i.e., their main business objective, transaction type, sales purpose and sales quantity. Entities that sell their products and services to business-to-customer (B2C) e-commerce businesses are classified as vendors, and these provide manufactured, processed or re-packed products and services to end customers (different service packages and varying levels of quality), which affect customer perceptions and satisfaction with e-commerce platforms. There is, therefore, a need to develop an effective e-vendor relationshipmanagement (eVRM) system which can locate and maintain vendors that provide a high quality of products and services, in order to strengthen the functions of e-commerce businesses and foster a positive atmosphere in $\mathrm{B} 2 \mathrm{C}$ e-commerce ecosystems.

Existing theories have demonstrated the essence of relationship quality in $\mathrm{B} 2 \mathrm{C}$ e-commerce (Zhang et al., 2011). In view of this, the particular contribution of this paper is to the domain of relationship management (RM), which is a systematic process for coordinating interactions between business entities, in order to increase trust and interdependence and to enhance engagement (Bullen et al., 2017). B2C e-commerce ecosystems need to maintain an effective platform-vendor-client relationship, based on well-researched platform-client and vendor-client relationships (Durai and Stella, 2017; Saunila et al., 2019). This paper contributes to the field by exploring systematic development of eVRM (rarely discussed in existing literature), drawing upon RM theories, in the context of global B2C e-commerce. However, managing a diverse group of vendors is an enormous challenge in terms of contract management and cost optimization (e.g., determining the most appropriate strategies for e-vendors and controlling costs incurred) (Majumder et al., 2017; Cleary and McLarney, 2019). Worse still, the above challenges become even more problematic due to the complexity of the global B2C e-commerce environment, with e-vendors offering a wide range of products and services on e-commerce platforms, in different cultural contexts and with different behavioural norms. The commercial activities of e-vendors can also be wide-ranging and frequently updated, such that data analytics in relation to e-vendors becomes relatively difficult. To effectively analyse a large group of vendors, a data-driven analytics technique is used to assign vendors to various clusters, and an artificial intelligence technique is used to establish specific and customized vendor-management strategies. In view of this, an adaptive e-vendor relationship-management system (AVRMS) is proposed here, which adopts the fuzzy c-means (FCM) clustering approach and case-based reasoning. Unlike $\mathrm{k}$-means clustering and c-means clustering, FCM clustering is more flexible when it comes to cluster formulation, and it can investigate the degree of belongingness rather than showing a Boolean result. Entities may not belong in only one cluster, and the relevance between entities and clusters should be quantified. Consequently, FCM clustering is deemed to be promising for assigning e-commerce vendors to a number of clusters according to several measurement dimensions, such as sales volume and product variety. Having done this, appropriate vendor management strategies can be established, aimed at attracting and maintaining positive relationships between vendors and e-commerce platforms using case-based reasoning. Previous strategies can be used as a reference when new strategies are being established for the management of e-vendor groups, whereas a closed-loop mechanism can be formulated for the eVRM. Thus, global B2C e-commerce businesses can be operated and developed in a holistic manner, taking into account the concerns of both vendors and customers so that their ecosystems can be more profitable and sustainable.

Our contribution has two facets. Firstly, this study attempts to fill the gap in terms of e-vendor relationship management in global B2C e-commerce, proposing a model that can identify, attract, develop and retain e-vendors while building mutual trust and reliable relationships. Existing studies focus on improving customer-vendor relationships and platform-customer relationships in order to boost sales and promote trust on e-commerce platforms (Durai and Stella, 2017; Saunila et al., 2019), but research into management of platform-vendor relationships is relatively rare. Without a reliable platform-vendor relationship, the trust circle between platforms, vendors and customers cannot be established effectively. Secondly, the integration of data-driven and artificial intelligence 
Table 1. Comparison of e-commerce suppliers and vendors

\begin{tabular}{|c|c|c|}
\hline & Suppliers & Vendors \\
\hline Objective & $\begin{array}{c}\text { Providing goods and services requested by } \\
\text { businesses }\end{array}$ & $\begin{array}{c}\text { Selling goods and services at a price to end } \\
\text { customers }\end{array}$ \\
\hline Transaction type & Business-to-business (B2B) & Business-to-customer (B2C) \\
\hline Sales purpose & Resale or value-added & Consumption \\
\hline Sales quantity & Bulk with a minimum order quantity & Small batch \\
\hline Example & $1688 . c o m$ & \\
\hline
\end{tabular}

approaches formulates a closed-loop mechanism, which facilitates eVRM functionalities, enabling a large group of e-vendors to be managed effectively so that the entire business ecosystem can be sustained. Functionalities supporting identification, attraction, development and retention of e-vendors can then be achieved in a systematic manner.

The remainder of this paper is organized as follows: Section 2 reviews the literature on B2C e-commerce, eVRM and emerging techniques for data analytics, and it summarizes the research gap that this study seeks to fill. Section 3 describes the system architecture of the proposed AVRMS. Section 4 presents a case study that validates the feasibility of the proposed system. Section 5 discusses results and the impact of the AVRMS case study. Lastly, Section 6 draws the conclusions of this paper.

\section{LITERATURE REVIEW}

In global e-commerce, there are four major types of e-commerce businesses and relationships, including business-to-customer (B2C), business-to-business (B2B), customer-to-customer (C2C) and customer-to-business (C2B) (Rouibah et al., 2015; Vyas and Gupta, 2017; Zhou et al., 2018). $\mathrm{B} 2 \mathrm{C}$ and $\mathrm{C} 2 \mathrm{~B}$ are the main modes of e-commerce business these days, but development of $\mathrm{C} 2 \mathrm{~B}$ remains limited and subject to government policy support, laws and regulations. In view of this, B2C e-commerce is still the most common and popular e-commerce business mode for provision of products and services to the general public. In the global business environment, B2C e-commerce businesses establish ecosystems in order to strike a balance between various stakeholder benefits, including vendors, customers and e-commerce platform management. Recent studies have focused on improving customer perceptions, platform operations and marketing strategies (Omondi and Mbugua, 2017; Cai et al., 2018; Maxwell and Khan, 2018; Campbell, 2019). Mutual trust and a profitable business model in B2C e-commerce can thus be established between stakeholders (Hong, 2018). However, most products and services sold on e-commerce platforms are not exclusively provided by single vendors, and thus multiple e-commerce vendors can sell the same or similar products and services in the marketplace. Although e-commerce vendors themselves have a business relationship with platforms, abiding by particular laws and regulations, the quality and variety differ from vendor to vendor. The products and services provided can directly affect customer satisfaction, platform image and the sustainability of a business model. Effective management of e-vendors on e-commerce platforms is, therefore, essential and critical in a global e-commerce environment (Wang et al., 2016; Kim and Peterson, 2017; Prashar et al., 2019). As with CRM, the management of e-vendors should cover identification, attraction, retention and development of high-quality e-vendors, in order to create a positive atmosphere in e-commerce businesses. E-vendors can select particular e-commerce platforms from the plethora available, in which to invest their resources and effort when exploring the e-commerce market. To effectively maintain a group of high-quality e-vendors, e-vendor relationship management (eVRM) should be established between e-vendors and e-commerce platforms within the existing globalized business environment. Recent studies have explored client-vendor relationships 
(CVR) among global providers of highly customized products and services (Sharma et al., 2016). The positive effects on CVR quality can be generated from knowledge management and a global mindset. In addition, Payen et al. (2016) examined the trust-commitment vendor relationship, and cooperation, coordination and relationship investments were found to positively relate to the trust and commitment of vendors. There is, therefore, room to explore and develop eVRM in global e-commerce, and data mining and data analytics techniques should be considered in order to differentiate between e-vendors when it comes to formulating appropriate vendor management strategies.

Due to the scale and complexity of data associated with e-vendor activities across different e-commerce platforms, straightforward data analysis is not appropriate for analysing vendor behaviour and performance. Data analytics techniques are needed to differentiate between vendors and to assign them to different categorizations. K-means clustering, k-modes clustering and k-median clustering are three typical techniques for classifying large groups of data into various clusters (Chaturvedi et al., 2001; Jain, 2010; Balcan et al., 2013). These three techniques are classified as hard-clustering techniques, whereby the degree of belongingness of clusters is presented in a binary form. In view of this, soft clustering techniques were selected for this study due to the fact that the degree of belonginess of data points can be measured in a fuzzy manner. When it comes to categorizing e-vendors, these characteristics enable investigation of belonginess in specific clusters and the tendency between various clusters, which is essential for managing high numbers of e-vendors within a global e-commerce network. FCM clustering is one of these techniques, which integrates fuzzy-set theory and c-means clustering in order to separate data into various clusters using fuzzy numbers (Bezdek et al., 1984). Recent studies have used FCM in several application areas to add value to businesses and enhance the decision-making process through classification of data points particular to e-commerce. FCM is deemed to be a promising technique for web-mining activities and to classify web documents, websites and users when formulating appropriate decision-making strategies (Song and Shepperd, 2006; Tang et al., 2018). Wang (2010) explored FCM in the field of customer relationship management to cluster customers according to their preferences, namely fees, credit, functions, reputation and promotion. Keskin (2015) made use of FCM to classify suppliers based on their performance in the areas of supplier selection and quality evaluation. Liu et al. (2019) adopted FCM to assess product-quality risk in an e-commerce environment, and they showed that it has robust feature-extraction capability. Thus, it is implied that FCM is capable of classifying e-vendors in a global e-commerce business environment, according to particular evaluation criteria. Adoption of FCM for e-VRM is currently limited, but it should be considered in order to enhance vendor management in a global e-commerce context. Effective clustering of e-vendors in e-commerce can be a means of focusing and retaining better relationships with loyal and sustainable vendors, and mutual trust relationships between e-commerce platforms and vendors can thus be established. When it comes to adopting FCM in e-vendor relationship management, the factors used in data clustering should be cross-referenced with the factors in vendor selection, such as environmental, economic, political and technological factors (Montazer et al., 2009; Govindan et al., 2015; Okwu and Tartibu, 2020). A performance and preference matrix can then be formulated in a balanced manner, which takes into account independent factors, and thus the ecosystem of global e-commerce businesses can be improved. In order to effectively establish appropriate management strategies for eVRM, case-based reasoning (CBR) is another promising technique which provides new solutions based on historical cases stored in the case library (Lee, 2019). With strategy formulation in particular, CBR plays an effective role in strategic decision-making among e-commerce businesses (En-Naimi and Zouhair, 2016; Gu and Tian, 2017).

The above studies have helped global e-commerce businesses to grow rapidly, expanding due to the convenience and variety of products and services on offer, and numerous e-commerce platforms have been launched, competing for customer loyalty and platform reputation. However, vendor management has received relatively little attention to date and is an area that could potentially improve e-commerce ecosystems globally. From the perspective of e-vendors, they select appropriate 
e-commerce platforms and invest certain levels of resources in order to promote their products and services. Effective e-vendor relationship management is, therefore, important for identifying loyal and sustainable e-vendors across platforms, and strategic relationships can be established in order to develop a better reputation and boost e-commerce profits. In the era of big data, integration of FCM and CBR is deemed to be suitable as a means of identifying, attracting, developing and retaining e-vendors, providing customized alliance strategies and company promotion. All in all, global e-commerce ecosystems can be developed in a positive and sustainable atmosphere.

\section{DESIGN OF AN ADAPTIVE E-VENDOR RELATIONSHIP-MANAGEMENT SYSTEM}

This section presents an adaptive e-vendor relationship-management system (AVRMS), which is designed to consolidate e-vendor information from e-commerce platforms, in order to formulate effective vendor segmentation and vendor relationship-management strategies. According to Espinosa et al. (2019), the adaptive system approach refers to an interconnected network of business entities, which perform adaptive actions subject to changes in the environment and the entities themselves. The adaptive system approach is considered in the methodology for the proposed system, which can respond to its environment and is capable of handling a number of e-vendors, strategy formation and eVRM complexity. Thus, the proposed system can adapt to different global B2C e-commerce environments and, in so doing, achieve effective eVRM. As shown in Figure 1, the architecture of the proposed system is described with three major modules, namely (i) the information acquisition module (IAM), (ii) the vendor clustering module (VCM) and (iii) vendor relationship-management module (VRMM).

\subsection{Information Acquisition Module (IAM)}

Numerous vendors register on e-commerce platforms so that they can provide their products and services to targeted customers. Some platforms subject their vendors to restrictions and requirements in order to filter potential, sustainable and high-quality vendors and create a win-win business situation mutually. Present-day e-commerce platforms manage vendor information and operational data in a cloud database with high accessibility, system scalability and flexibility. However, the total volume of data related to vendors is tremendous, making it is difficult to analyse effectively and to generate meaningful outcomes. In view of this, before applying clustering, data pre-processing is required, including data cleaning, editing, reduction and wrangling. Missing and uncertain data can be modified to fit the data-mining and data-analysis process. To retrieve key information regarding vendors, standard vendor-selection criteria can be applied to establish an appropriate vendor performance matrix for the clustering process. Figure 2 shows an entity relationship diagram of essential information for operating B2C e-commerce platforms and the relationship between customers, vendors, products and services. Data stored in the cloud database need further processing before the vendor evaluation matrix can be formulated, considering several vendor selection criteria. In terms of work (Chang et al., 2011), the selection process involves ten essential criteria, namely quality, service, flexibility, price, delivery, lead time, reaction to changes in demand, production capability, technical capability and the reliability of delivery. It, therefore, deduces eight evaluation factors for e-vendors in a global e-commerce environment, including years in business, profitability, stability, flexibility, sustainability, financial stability, level of customization and customer service. These factors can be used to formulate the vendor evaluation matrix $\left(\mathbf{E}=\left(x_{i j}\right) \in \mathbb{R}^{v \times d}\right)$, where $v$ denotes the number of vendors, and $d$ represents the number of vendor evaluation factors, in order to assign vendors to different clusters. 


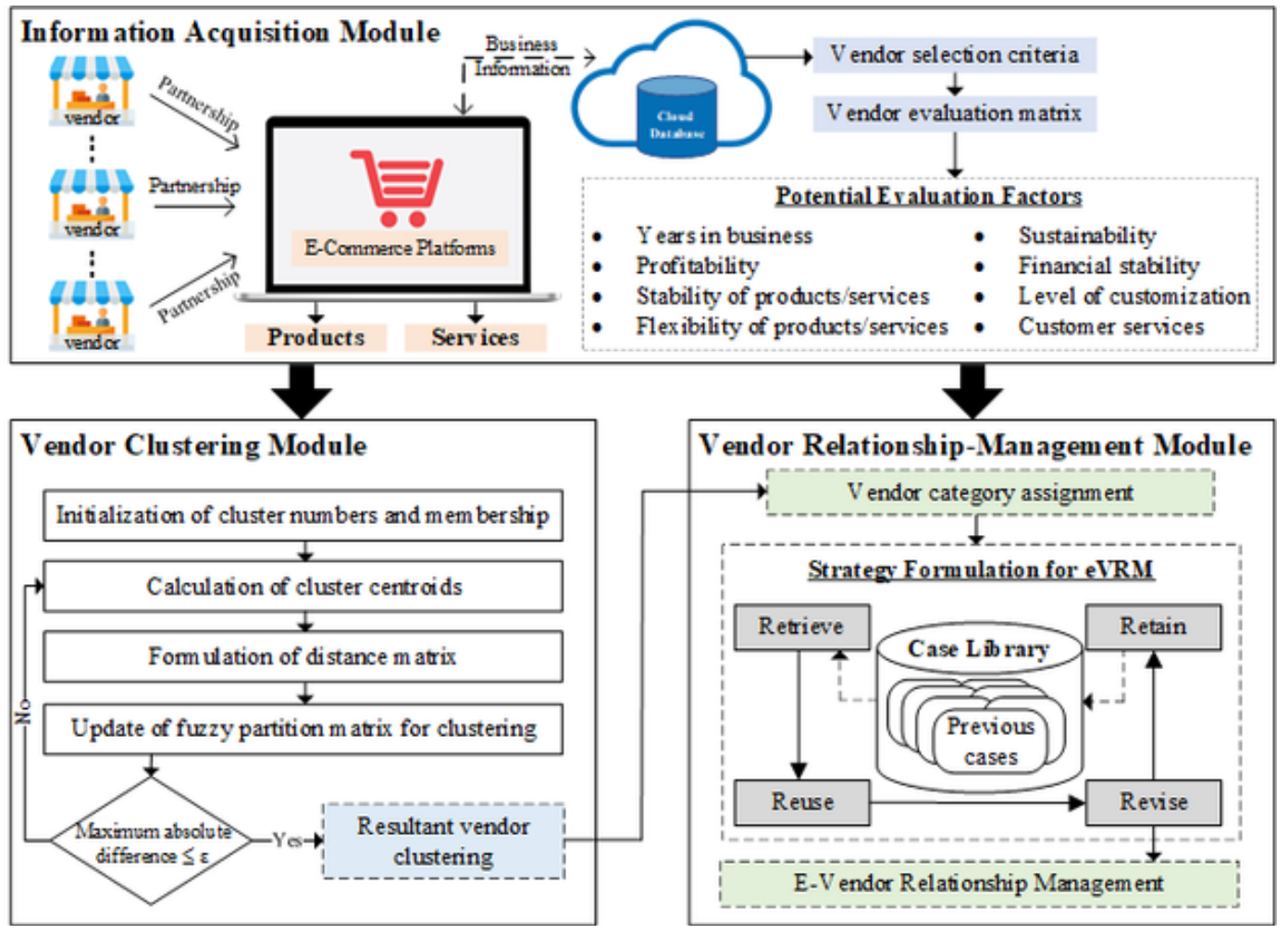

Figure 2. Entity relationship diagram for operating B2C e-commerce platforms

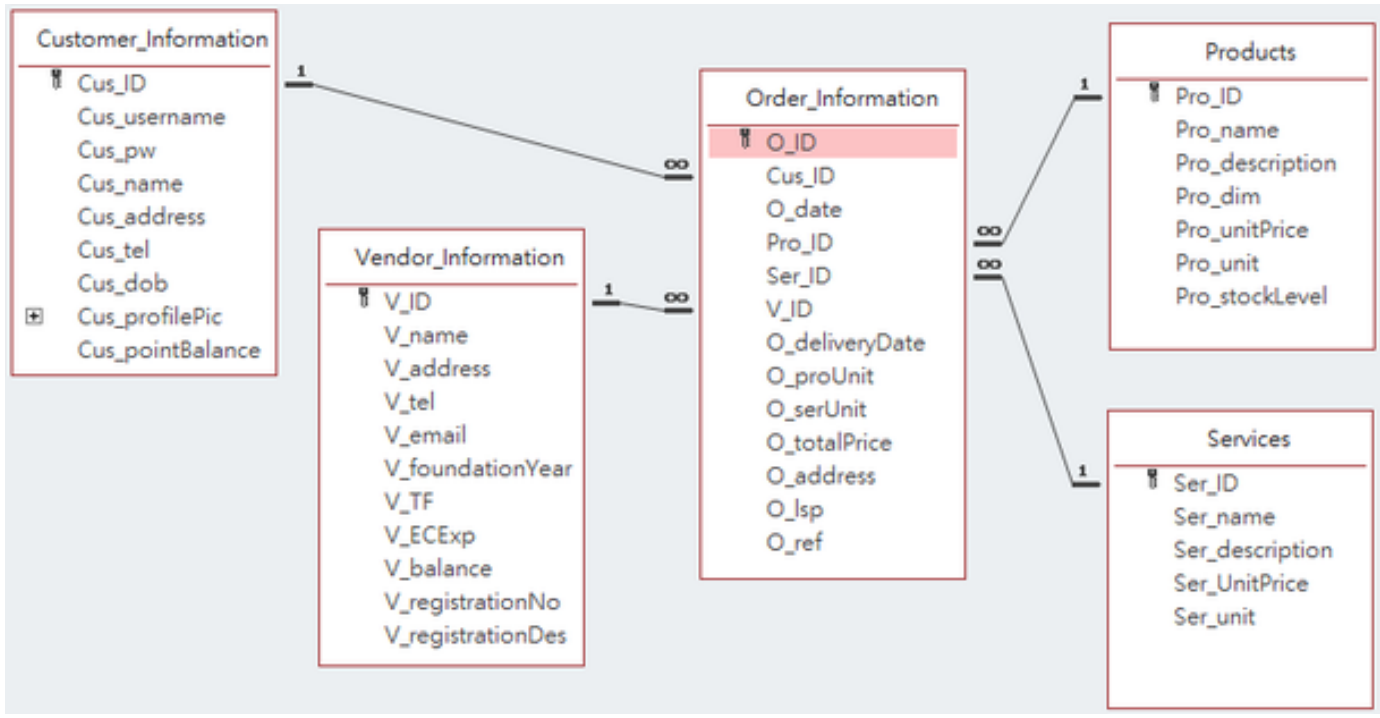




\subsection{Vendor Clustering Module (VCM)}

After formulating the vendor evaluation matrix (E), the fuzzy c-means clustering approach is then applied to classify vendors and investigate their degree of belongingness to clusters. To group $v$ vendors into $c$ classifications, an objective function $\left(J_{m}\right)$ with a fuzzy partition matrix $(\tilde{U})$ and set of cluster centres $\left(\mathbf{z}=\left\{z_{i 1}, z_{i 2}, \ldots, z_{i m}\right\}\right)$ is established to minimize iterative errors, as in (1). $\mu_{i k}$ and $d_{i k}$ denote the membership value and distance between data points and cluster centres of the $k^{\text {th }}$ data point in the $i^{\text {th }}$ class, respectively. The amount of fuzziness in the clustering process is controlled by the weighting parameter $m^{\prime} \in[1, \infty)$ :

$$
J_{m}(\tilde{\mathbf{U}}, \mathbf{z})=\sum_{k=1}^{v} \sum_{i=1}^{c}\left(\mu_{i k}\right)^{m^{\prime}}\left(d_{i k}\right)^{2}
$$

In addition, the distance between data points $\left(x_{k}\right)$ and cluster centres $\left(z_{i}\right)$ is expressed as in (2) for $m$ vendor-evaluation dimensions. In the FCM approach, there are four major steps for obtaining clustering results, as shown in Figure 1, including (i) initialization of the cluster number and fuzzy partition matrix; (ii) calculation of the cluster-centre coordinates; (iii) formulation of the distance matrix; and (iv) updating the fuzzy partition matrix:

$$
d_{i k}=\left[\sum_{j=1}^{m}\left(x_{k j}-z_{i j}\right)^{2}\right]^{\frac{1}{2}}
$$

At the beginning, the cluster numbers $c \in[2, v]$ should be determined (which cannot be greater than the number of vendors in the clustering problems), and the weighting parameter $m$ ' in $J_{m}$ should be chosen. Next, the fuzzy partition matrix can be randomly initialized as $\tilde{\mathbf{U}}^{(0)}$, and the iterative process is labelled by using $r \in \mathbb{N} \cup\{0\}$. The fuzzy characteristics of vendors in specific clusters are defined between 0 and 1 , which can be further interpreted by the fuzzy numbers (such as triangular and trapezoid shapes) in order to understand the belongingness in clusters. It is implied that the higher the values of fuzzy characteristics are, the higher the belongingness of the clusters will be. The sum of the degree of belongingness of each vendor to clusters is equal to 1, i.e., $\sum_{j=1}^{v} u_{i j}=1, \forall i \in c$ and thus membership values in the fuzzy partition matrix directly imply the degree of belongingness to clusters. The cluster centres, including the initial cluster centres $\mathrm{z}_{i}^{(0)}$ can then be formulated using (3), and a set of coordinates for cluster centres can be determined. The values of cluster centres are applied to measure the Euclidean distance of each data point from each cluster centre (in relation to vendor performance) using (2). The performance of the Euclidean distance measurement in FCM has been proven, and it outperforms other distance measurements, such as Mahalanobis distance and Minkowski distance, for most scenarios (Arora et al., 2019). Thus, a distance matrix based on vendor performance and cluster centres can be constructed. By using the distance matrix, the fuzzy partition matrix can be updated to $\tilde{\mathbf{U}}^{(r+1)}$, where the membership values for $r+1$ iterations in the matrix are expressed in (4). To measure the optimality of the problem, a criterion for convergence $(\varepsilon)$ is set. If maximum absolute errors of membership values between two successive fuzzy partition matrices (i.e., $\tilde{\mathbf{U}}^{(r)}$ and $\tilde{\mathbf{U}}^{(r+1)}$ ) are less than $\varepsilon$, the FCM iterative process is terminated, and the finalized fuzzy partition matrix can be obtained. Otherwise, the coordinates of cluster centres are re-evaluated based on the updated fuzzy partition matrix, and the fuzzy partition matrix is updated continuously. The finalized fuzzy partition matrix shows the degree of belongingness of vendors to clusters, with a 
value between 0 and 1 , and vendors are assigned to the designated cluster with the highest membership values of all other clusters. Overall, iterative optimization is an effective means of classifying vendors into different clusters:

$$
\mathrm{z}_{i j}=\frac{\sum_{k=1}^{v} \mu_{i k}^{m^{\prime}} \cdot x_{k j}}{\sum_{k=1}^{v} \mu_{i k}^{m^{\prime}}}
$$

$$
\tilde{\mathbf{U}}^{(r+1)}=\mu_{i k}^{(r+1)}=\left[\sum_{j=1}^{c}\left(\frac{d_{i k}^{(r)}}{d_{j k}^{(r)}}\right)^{\frac{2}{m^{\prime}-1}}\right]^{-1}
$$

\subsection{Vendor Relationship-Management Module (VRMM)}

Although vendors are classified into different clusters, the categories of the clusters need to be assigned in a systematic manner in order to add value to businesses in VRM. In the resultant clusters, vendor performance indicators are aggregated to generate relevance scores for three pre-determined categories, namely a very important person (VIP), a premium vendor (PV) or a standard vendor (SV). Since vendors are measured according to various dimensions with different scales, data normalization is necessary for integration and comparison of data points with one another. Normalization can convert numerical values from different scales to a range based on a notionally common scale. Compared with other normalization methods (such as z-score normalization and coefficient of variation), min-max normalization (a unity-based approach) confines values to $a$ or $b$, where $a$ and $b$ are two arbitrary points, and $a<b$. Thus, min-max normalization is deemed effective for restricting different scales and guaranteeing all features on a common scale for further combination and analysis. Among various dimensions in the vendor evaluation matrix, min-max normalization is applied to generate normalized vendor-performance indicators $\left(n_{i j}\right)$ for each dimension of feature spaces, as in (5). This provides numerical scaling (between 0 and 1 ) for each vendor in relation to the performance dimensions:

$$
n_{i j}=\frac{x_{i j}-\min \left(x_{j}\right)}{\max \left(x_{j}\right)-\min \left(x_{j}\right)}
$$

Once integrated with the clustering results, normalized vendor-performance indicators are averaged and aggregated in order to obtain a relevance score $(R)$. Equation (6) describes the aggregation process using a weighted arithmetic mean to calculate the relevance score for cluster $(c)$. The categories and ranking of clusters are assigned according to the relevance score of clusters:

$$
R=\omega_{1} n_{i 1}^{(c)}+\omega_{2} n_{i 2}^{(c)}+\ldots+\omega_{l} n_{i l}^{(c)}
$$

By grouping vendors, e-vendor relationship management can be applied to maintain the ecosystem of e-commerce businesses, while appropriate eVRM strategies can be formulated for specific vendor clusters. To achieve the above results, a CBR approach is thus applied in a systematic manner, with four stages, namely retrieval, reuse, revision and retention. When e-vendors have been clustered into 
the three categories (VIP, PV or SV), previous strategies can be retrieved, values can be attributed in terms of their similarity $\left(S_{i}\right)$ to the new groups of vendors, and these values can be evaluated as in equation (7), where $f_{i}^{n}$ and $f_{i}^{o}$ denote the value of the attribute $(i)$ for new and old cases, and $w_{i}$ represents the weights of individual attributes. On the basis of the similarity values calculated, one of the previous strategies can be reused for formulation of eVRM strategies, and the content of these strategies can then be revised by domain experts so that confirmed strategies can be generated accordingly. Lastly, the confirmed strategies can be retained in the case library for future retrieval:

$$
S_{i}=\frac{\sum_{i=1}^{n} w_{i} \cdot \operatorname{sim}\left(f_{i}^{n}, f_{i}^{o}\right)}{\sum_{i=1}^{n} w_{i}}, \text { where } \operatorname{sim}\left(f_{i}^{n}, f_{i}^{o}\right)=\frac{\min \left(\left|f_{i}^{n}\right|,\left|f_{i}^{o}\right|\right)}{\max \left(\left|f_{i}^{n}\right|,\left|f_{i}^{o}\right|\right)}
$$

The objectives of eVRM are to achieve long-term relationships and establish win-win situations with the vendors while providing technological support, vendor rewards and adequate training. When setting up stores on e-commerce platforms, service agreements between vendors and e-commerce platforms are established, covering the discount to be given in various payment gateways, sales commission on transactions, customer service levels and legal liability in transactions. These elements can be considered when formulating customized eVRM strategies with vendors so that vendors are more willing to invest their resources and time in e-commerce platforms. Relationships between vendors and e-commerce platforms can evolve from an electronic landlord-tenant relationship to a strategic alliance relationship.

\section{CASE STUDY}

To validate the proposed system in a real-life situation, a company located in Hong Kong was selected to trial the AVRMS as a means of managing their vendors operating B2C e-commerce businesses. This case study will provide a point of reference for other companies operating global B2C e-commerce businesses (in which numerous customers and vendors are managed) and will provide insights into effective relationship management strategies with vendors, which are currently lacking. In brief, three selection criteria of the case company are (i) operating business of global B2C e-commerce, (ii) extensive customers and vendors in the platform, and (iii) lack of effective relationship management to vendors. For the selected company in this case study, fifty vendors were selected who were selling goods and services on e-commerce platforms, and these vendors were included in the eVRM programme. This section covers two stages, namely (i) the company in this case study and its problems, and (ii) implementation of the AVRMS.

\subsection{The Company in the Case Study and Its Problems}

The company in this case study operates a B2C e-commerce and m-commerce platform selling physical products to end customers, including general commodities, food and beverages, and electronics products. The aim of its business is to provide high-quality, economical goods to end customers. In the current global e-commerce environment, e-commerce platforms must have unique features and characteristics in order to be attractive to end customers and to stand out from existing e-commerce platforms. The business model of the company in our case study involves sourcing high-quality, international products rather than just selling anonymous or counterfeit products. It hoped to create mutual trust relationships between end customers and the platform. The company, therefore, carried out an in-depth and systematic vendor-selection analysis to select and invite high-quality vendors to join the platform. Due to the expansion of its business and global business development, a great many vendors were contracted to the e-commerce platform, but the company lacked the capacity 
to manage all its vendors effectively. Consequently, the relationship between platforms and vendors was weak, so much so that some vendors had ceased trading on the e-commerce platform, and others treated the platform as a kind of marketing or promotional channel. Platforms cannot grow without a group of reliable vendors, and this becomes a challenge in global e-commerce. The company in our case study was, therefore, willing to seek a way of managing and maintaining vendor relationships effectively so that its global e-commerce business could be more sustainable and resilient.

\subsection{Implementation of the AVRMS}

To implement the proposed AVRMS in the company, we followed the implementation roadmap shown in Figure 3, which has three steps, namely (i) formulation of vendor performance analysis, (ii) deployment of fuzzy c-means clustering for vendor classification and (iii) establishment of eVRM strategies.

In step one of this model (and based on the vendor selection criteria), the vendor evaluation matrix is formulated to assess vendor features and performance on the e-commerce platform. In this case study, evaluation factors were deduced from the eight factor categories for the eVRM, as shown in Figure 4, and the company was found to measure e-vendors in its global e-commerce business in terms of how many years they had been in business, their profitability and level of customization. The company was willing to disclose three factors relating to the fifty vendors in our investigation, i.e., how long the vendors had been in business ( $f_{1}$ ) (ranging from 0 to 10 years), stock-keeping units (SKUs) for their product ranges $\left(\mathrm{f}_{2}\right)$ (ranging from 1 to $30 \mathrm{SKUs}$ ) and monthly sales volume $\left(\mathrm{f}_{3}\right)$ (ranging from $\$ 0$ to $\$ 100,000$ ), as shown in the Appendix. For a better understanding of the scenario, the data collected were visualized and are shown in Figure 5. Data for $f_{1}$ and $f_{2}$ could be directly collected from the e-commerce platform on a regular monthly basis, and $\mathrm{f}_{3}$ was the total monthly sales volume for each e-vendor.

The objective of the proposed system is to group vendors into three pre-determined categories (i.e., VIP, PV or SV) and to formulate customized VRM strategies. In this case study, the weighting parameter (m') was assumed to be 2 , and the criterion of convergence $(\varepsilon)$ was 0.01 for the VCM process. The initial fuzzy partition matrix was then formulated to begin the FCM process, as in (7),

Figure 3. Implementation roadmap for the AVRMS

\section{Implementation Flow}

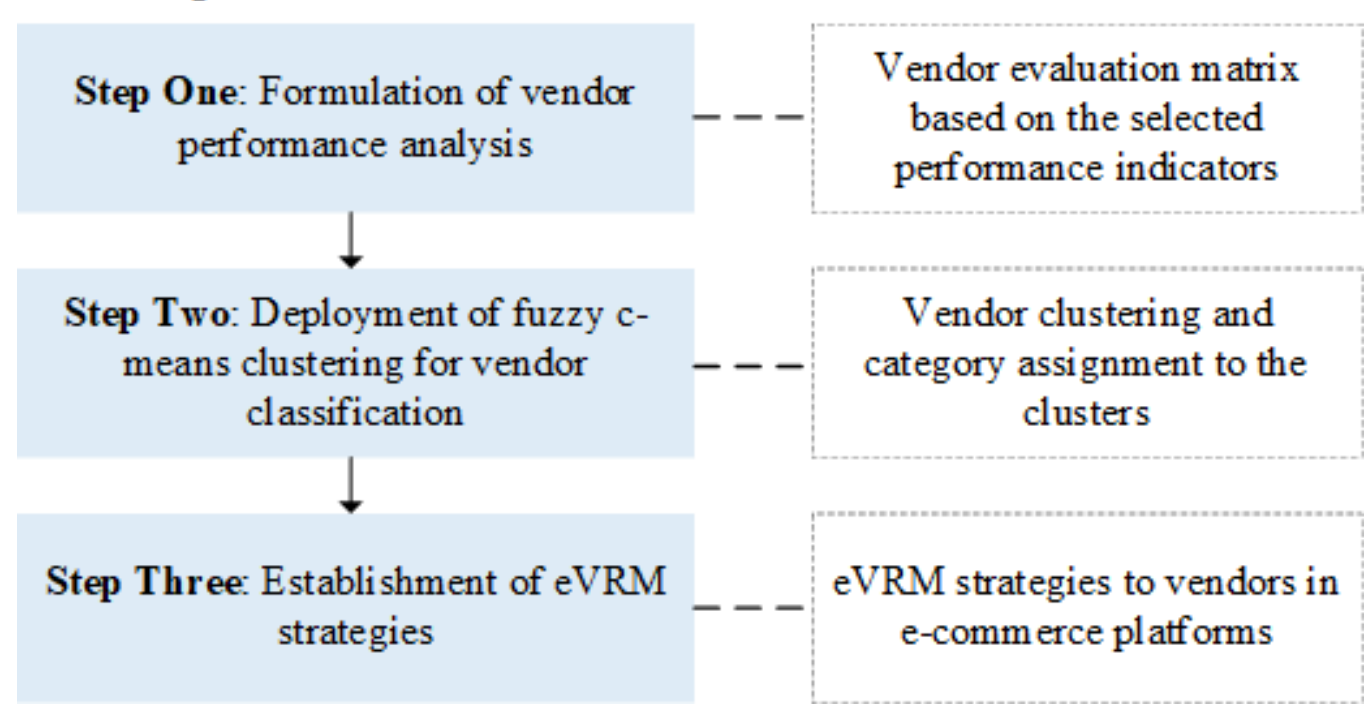


Figure 4. Evaluation factors for e-vendor relationship management

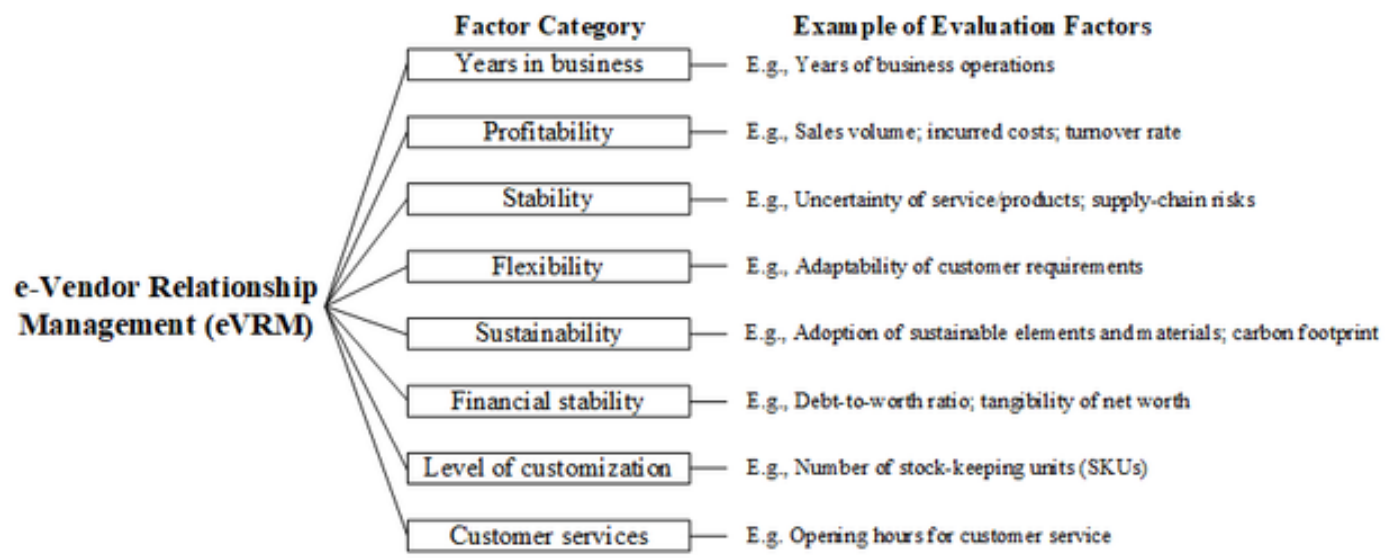

Figure 5. Vendor performance in three selected dimensions

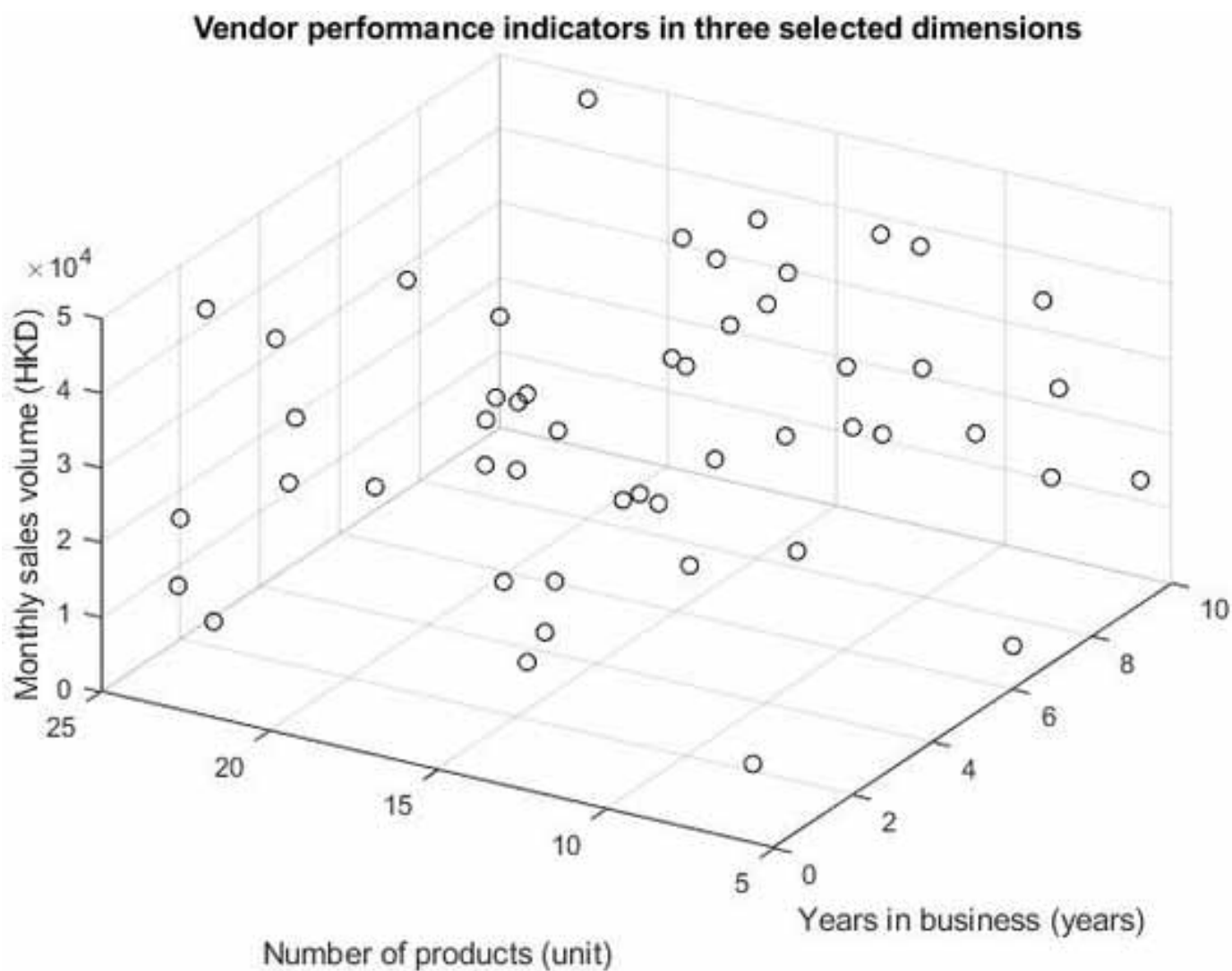

where the fifty vendors were labelled by using $v=\left\{v_{1}, v_{2}, \ldots, v_{50}\right\}$. Secondly, vendors were randomly assigned to one of the clusters. By using the vendor evaluation matrix and initial fuzzy partition matrix, the coordinates of cluster centres could be measured, as shown in Table 2, e.g., the coordinate of cluster 1 in the feature space of factor 1 , the sum of product values in $f_{1}$ and the square of the fuzzy 
partition matrix in cluster 1 , namely $\left(8.27 \times 1^{2}+8.80 \times 0^{2}+\ldots+7.90 \times 0^{2}\right) /\left(1^{2}+0^{2}+\ldots+0^{2}\right)=$ 5.23. Based on the initial cluster centres, the Euclidean distance between vendor performance data points and cluster centres could be evaluated to formulate a distance matrix, as shown in Table 3. For example, the distance between vendor 1 and cluster 1 was calculated as $\left[(8.70-5.23)^{2}+(17\right.$ $\left.-15.06)^{2}+(35443.5-27263.12)^{2}\right]^{0.5}=8180.38$. The distance matrix was then used to update the fuzzy partition matrix, indicating the degree of belongingness of vendors to clusters, as shown in Table 4. For instance, updating a member of the fuzzy partition matrix for vendor 1 in cluster 1 was followed by equation (4), namely $\left((8180.38 / 8180.38)^{2}+(8180.38 / 8344.10)^{2}+(8180.38 / 11352.35)^{2}\right)^{-1}$ $=0.4032$. The iterative optimization process was repeated to locate the updated cluster centres by using the new fuzzy partition matrix when the criterion of convergence was not met:

$$
\tilde{\mathbf{U}}^{(0)}=\left[\begin{array}{cccccccccc} 
& v_{1} & v_{2} & v_{3} & v_{4} & v_{5} & v_{6} & & v_{49} & v_{50} \\
c_{1} & 1 & 0 & 0 & 1 & 0 & 0 & \cdots & 1 & 0 \\
c_{2} & 0 & 1 & 0 & 0 & 1 & 0 & \cdots & 0 & 1 \\
c_{3} & 0 & 0 & 1 & 0 & 0 & 1 & \cdots & 0 & 0
\end{array}\right]
$$

On reaching the nineth iteration, the clustering problem was converged, and the resultant fuzzy partition matrix could be found, as shown in Table 5. The highest fuzziness values for each vendor were marked with an asterisk to indicate the appropriate clusters after clustering. The fifty vendors could be grouped into three separate clusters according to their performance and features. Moreover, the fuzziness values between vendors and cluster centre showed the extent of changing cluster membership (i.e., vendors entering and leaving respective clusters). Vendors with a lower degree of belongingness in clusters have a higher likelihood of being moved into another cluster when more vendor information is taken into consideration. From Table 5, it can be seen that 12 vendors belong to cluster 1 (V4, V5, V17, V29, V32, V37, V42, V43, V45, V47, V48 and V49); 17 vendors belong to cluster 2 (V1, V2, V3, V8, V9, V10, V13, V14, V18, V21, V25, V26, V35, V36, V40, V41 and V46); and 21 vendors belong to cluster 3 (V6, V7, V11, V12, V15, V16, V19, V20, V22, V23, V24, V27, V28, V30, V31, V33, V34, V38, V39, V44 and V50). The three categories were then assigned to clusters to ascertain the meaning and implications of the clustering results so that correlations between the VIP, PV and SV categories and clusters could be established. Based on the clustered data, min-max normalization was applied to standardize data in the clusters, and the relevance scores of the clusters could, therefore, be measured, revealing that the weightings in three vendor evaluation factors were $0.4\left(\omega_{1}\right), 0.3\left(\omega_{2}\right)$ and $0.3\left(\omega_{3}\right)$, respectively. For example, in cluster $1\left(c_{1}\right)$, the average values of $f_{1}, f_{2}$ and $f_{3}$ were $0.507,0.425$ and 0.936 , respectively, and thus the relevance score of cluster 1 was $0.507 \times 0.4+0.425 \times 0.3+0.936 \times 0.3=0.611$. In turn, application of equation (6) produced relevance scores of $0.611,0.581$ and 0.447 for $\mathrm{c}_{1}, \mathrm{c}_{2}$ and $\mathrm{c}_{3}$, respectively, thus, $\mathrm{c}_{1}, \mathrm{c}_{2}$ and $\mathrm{c}_{3}$ were labelled as VIP, PV and SV, respectively. Finally, the results of vendor clustering and category assignment were obtained, as shown in Figure 6.

Table 2. Cluster-centre coordinates for the three factor spaces (first iteration)

\begin{tabular}{|c|c|c|c|}
\hline zij & Factor $\mathbf{1}\left(\mathbf{f}_{\mathbf{1}}\right)$ & Factor 2 $\left(\mathbf{f}_{\mathbf{2}}\right)$ & Factor 3 $\left(\mathbf{f}_{\mathbf{3}}\right)$ \\
\hline Cluster $\mathbf{1}\left(\mathbf{c}_{\mathbf{1}}\right)$ & 5.23 & 15.06 & 27263.12 \\
\hline Cluster 2 $\left(\mathbf{c}_{\mathbf{2}}\right)$ & 5.74 & 13.35 & 27099.41 \\
\hline Cluster 3 $\left(\mathbf{c}_{\mathbf{3}}\right)$ & 5.53 & 17.69 & 24091.15 \\
\hline
\end{tabular}


Table 3. Distance matrix showing vendors and cluster centres (first iteration)

\begin{tabular}{|c|c|c|c|c|c|c|c|}
\hline Distance & c1 & c2 & c3 & & c1 & c2 & c3 \\
\hline V1 & 8180.38 & 8344.10 & 11352.35 & V26 & 6436.48 & 6600.19 & 9608.45 \\
\hline $\mathbf{V} 2$ & 496.25 & 332.53 & 2675.76 & V27 & 20089.22 & 19925.51 & 16917.25 \\
\hline V3 & 8710.28 & 8873.99 & 11882.25 & V28 & 14469.33 & 14305.61 & 11297.35 \\
\hline V4 & 21955.18 & 22118.89 & 25127.15 & V29 & 18634.48 & 18798.20 & 21806.45 \\
\hline V5 & 17116.18 & 17279.89 & 20288.15 & V30 & 17589.23 & 17425.51 & 14417.25 \\
\hline V6 & 18392.72 & 18229.01 & 15220.75 & V31 & 10206.02 & 10042.31 & 7034.05 \\
\hline V7 & 15312.32 & 15148.61 & 12140.35 & V32 & 13918.38 & 14082.10 & 17090.35 \\
\hline V8 & 4908.19 & 5071.90 & 8080.16 & V33 & 19793.42 & 19629.71 & 16621.45 \\
\hline V9 & 4414.49 & 4578.21 & 7586.45 & V34 & 9003.23 & 8839.51 & 5831.25 \\
\hline V10 & 2837.53 & 2673.81 & 334.46 & V35 & 9308.08 & 9471.80 & 12480.05 \\
\hline V11 & 24956.23 & 24792.51 & 21784.25 & V36 & 576.97 & 740.69 & 3748.86 \\
\hline V12 & 11116.33 & 10952.61 & 7944.35 & V37 & 21898.28 & 22061.99 & 25070.25 \\
\hline V13 & 7874.98 & 8038.70 & 11046.95 & V38 & 17871.02 & 17707.31 & 14699.05 \\
\hline V14 & 2164.98 & 2328.70 & 5336.95 & V39 & 15914.63 & 15750.91 & 12742.65 \\
\hline V15 & 10601.63 & 10437.91 & 7429.66 & V40 & 4166.48 & 4330.20 & 7338.45 \\
\hline V16 & 16180.73 & 16017.01 & 13008.75 & V41 & 1831.54 & 1667.82 & 1340.49 \\
\hline V17 & 18064.68 & 18228.40 & 21236.65 & V42 & 18105.48 & 18269.19 & 21277.45 \\
\hline V18 & 2325.78 & 2489.50 & 5497.76 & V43 & 20072.98 & 20236.69 & 23244.95 \\
\hline V19 & 24839.12 & 24675.41 & 21667.15 & V44 & 16517.52 & 16353.81 & 13345.55 \\
\hline V20 & 21426.73 & 21263.01 & 18254.75 & V45 & 22002.98 & 22166.70 & 25174.95 \\
\hline V21 & 6249.42 & 6085.71 & 3077.46 & V46 & 8123.18 & 8286.89 & 11295.15 \\
\hline V22 & 26185.12 & 26021.41 & 23013.15 & V47 & 15063.58 & 15227.29 & 18235.55 \\
\hline V23 & 15785.63 & 15621.91 & 12613.65 & V48 & 20819.88 & 20983.60 & 23991.85 \\
\hline V24 & 7960.73 & 7797.01 & 4788.76 & V49 & 19138.98 & 19302.69 & 22310.95 \\
\hline V25 & 7622.98 & 7786.70 & 10794.95 & V50 & 9513.32 & 9349.61 & 6341.35 \\
\hline
\end{tabular}

Consequently, in the case of the VIP group, the 12 vendors performed best on the relevance score for the three evaluation factors, so a certain level of privilege should be granted to them. In the case of the PV group, the 17 vendors also performed well in B2C e-commerce so should be afforded some benefit in terms of support for their continued business operations. The performance of the SV group was relatively ordinary and was unremarkable in comparison to the others, so basic collaboration packages and management strategies should be applied to them.

Thirdly, after grouping vendors into various clusters, the customized VRM strategies could be formulated in order to maintain high-quality relationships and alliances between vendors and e-commerce platforms. Through the CBR mechanism, the similarity value of the VIP, PV and SV cases was measured in terms of (i) relevance scores, (ii) the number of members in clusters and (iii) the average values of $f_{1}, f_{2}$ and $f_{3}$, where the weights of the five attributes were equally assigned, i.e., 0.2. The process of retrieving historical strategies and calculating similarity values (illustrated in Figure 7) enabled the most relevant strategies to be selected for further revision and the creation of new eVRM strategies. The VRM programme covers four major areas, namely transaction offer, 
Table 4. Fuzzy partition matrix for vendors and cluster centres (first iteration)

\begin{tabular}{|c|c|c|c|c|c|c|c|}
\hline Fuzziness & c1 & c2 & c3 & & c1 & c2 & c3 \\
\hline V1 & $0.4032 *$ & 0.3875 & 0.2093 & V26 & $0.4167 *$ & 0.3963 & 0.1870 \\
\hline V2 & 0.3066 & $0.6829 *$ & 0.0105 & V27 & 0.2918 & 0.2966 & $0.4115^{*}$ \\
\hline V3 & $0.3999 *$ & 0.3853 & 0.2149 & V28 & 0.2730 & 0.2793 & $0.4478 *$ \\
\hline V4 & $0.3638 *$ & 0.3584 & 0.2778 & V29 & $0.3686^{*}$ & 0.3622 & 0.2692 \\
\hline V5 & $0.3713^{*}$ & 0.3643 & 0.2643 & V30 & 0.2851 & 0.2905 & $0.4244^{*}$ \\
\hline V6 & 0.2875 & 0.2927 & $0.4198 *$ & V31 & 0.2417 & 0.2496 & $0.5087 *$ \\
\hline V7 & 0.2768 & 0.2828 & $0.4404 *$ & V32 & $0.3788^{*}$ & 0.3700 & 0.2512 \\
\hline V8 & $0.4338 *$ & 0.4062 & 0.1600 & V33 & 0.2911 & 0.2960 & $0.4129 *$ \\
\hline V9 & $0.4408^{*}$ & 0.4099 & 0.1493 & V34 & 0.2262 & 0.2346 & $0.5392 *$ \\
\hline V10 & 0.0135 & 0.0152 & $0.9713^{*}$ & V35 & $0.3965^{*}$ & 0.3829 & 0.2206 \\
\hline V11 & 0.3007 & 0.3047 & $0.3946^{*}$ & V36 & $0.6133^{*}$ & 0.3722 & 0.0145 \\
\hline V12 & 0.2507 & 0.2583 & $0.4910^{*}$ & V37 & $0.3639 *$ & 0.3585 & 0.2776 \\
\hline V13 & $0.4052 *$ & 0.3889 & 0.2059 & V38 & 0.2860 & 0.2913 & $0.4227 *$ \\
\hline V14 & $0.4929 *$ & 0.4260 & 0.0811 & V39 & 0.2793 & 0.2851 & $0.4356^{*}$ \\
\hline V15 & 0.2458 & 0.2536 & $0.5006^{*}$ & V40 & $0.4448 *$ & 0.4118 & 0.1434 \\
\hline V16 & 0.2803 & 0.2861 & $0.4337^{*}$ & V41 & 0.2455 & 0.2961 & $0.4584 *$ \\
\hline V17 & $0.3696^{*}$ & 0.3630 & 0.2674 & V42 & $0.3695^{*}$ & 0.3629 & 0.2676 \\
\hline V18 & $0.4874 *$ & 0.4254 & 0.0872 & V43 & $0.3664 *$ & 0.3605 & 0.2732 \\
\hline V19 & 0.3005 & 0.3045 & $0.3950 *$ & V44 & 0.2815 & 0.2872 & $0.4313 *$ \\
\hline V20 & 0.2947 & 0.2993 & $0.4060 *$ & V45 & $0.3637 *$ & 0.3584 & 0.2779 \\
\hline V21 & 0.1619 & 0.1707 & $0.6675^{*}$ & V46 & $0.4035^{*}$ & 0.3877 & 0.2087 \\
\hline V22 & 0.3024 & 0.3062 & $0.3915^{*}$ & V47 & $0.3758 *$ & 0.3678 & 0.2564 \\
\hline V23 & 0.2788 & 0.2846 & $0.4366^{*}$ & V48 & $0.3653 *$ & 0.3596 & 0.2751 \\
\hline V24 & 0.2081 & 0.2169 & $0.5750^{*}$ & V49 & $0.3678^{*}$ & 0.3616 & 0.2706 \\
\hline V25 & $0.4070 *$ & 0.3901 & 0.2030 & V50 & 0.2333 & 0.2416 & $0.5251 *$ \\
\hline
\end{tabular}

platform functionalities, logistics services and customer service support, as shown in Table 6 . The vendor segments produced by the IAM and VCM indicated that at the time of our case study, the company was providing different offers to create mutually beneficial relationships with vendors and to enable them to do business more easily. In addition, the vendor service models were standardized to eliminate barriers to designing and packaging vendors' services and products. The finalized strategies for eVRM could then be stored in the case library for another retrieval process at a later date, using the CBR mechanism.

\section{RESULTS AND DISCUSSION}

After deployment of the proposed AVRMS system, e-vendors can be managed effectively on e-commerce platforms, and thus the ecosystem of a B2C e-commerce business can be better understood, and beneficial relationships with vendors and customers can be maintained. The proposed methodology in this paper has been proven in terms of identifying, attracting, developing and retaining 
Table 5. Resultant fuzzy partition matrix for vendors and cluster centres

\begin{tabular}{|c|c|c|c|c|c|c|c|}
\hline Fuzziness & c1 & c2 & c3 & & c1 & c2 & c3 \\
\hline V1 & 0.1397 & $0.8349 *$ & 0.0255 & V26 & 0.0423 & $0.9456^{*}$ & 0.0120 \\
\hline V2 & 0.0441 & $0.8943 *$ & 0.0616 & V27 & 0.0066 & 0.0176 & $0.9758^{*}$ \\
\hline V3 & 0.1834 & $0.7877^{*}$ & 0.0289 & V28 & 0.0051 & 0.0170 & $0.9779 *$ \\
\hline V4 & $0.9661 *$ & 0.0278 & 0.0061 & V29 & $0.9997 *$ & 0.0003 & 0.0000 \\
\hline V5 & $0.9802 *$ & 0.0172 & 0.0026 & V30 & 0.0004 & 0.0011 & $0.9985^{*}$ \\
\hline V6 & 0.0016 & 0.0046 & $0.9938^{*}$ & V31 & 0.0412 & 0.1774 & $0.7815^{*}$ \\
\hline V7 & 0.0021 & 0.0067 & $0.9912^{*}$ & V32 & $0.7897 *$ & 0.1899 & 0.0205 \\
\hline V8 & 0.0062 & $0.9913^{*}$ & 0.0025 & V33 & 0.0056 & 0.0149 & $0.9795^{*}$ \\
\hline V9 & 0.0018 & $0.9974^{*}$ & 0.0008 & V34 & 0.0547 & 0.2594 & $0.6858^{*}$ \\
\hline V10 & 0.0710 & $0.7591^{*}$ & 0.1698 & V35 & 0.2406 & $0.7273^{*}$ & 0.0321 \\
\hline V11 & 0.0305 & 0.0708 & $0.8986^{*}$ & V36 & 0.0292 & $0.9387^{*}$ & 0.0321 \\
\hline V12 & 0.0311 & 0.1258 & $0.8430 *$ & V37 & $0.9672 *$ & 0.0270 & 0.0059 \\
\hline $\mathrm{V} 13$ & 0.1176 & $0.8592 *$ & 0.0232 & V38 & 0.0007 & 0.0021 & $0.9972 *$ \\
\hline V14 & 0.0095 & $0.9832 *$ & 0.0073 & V39 & 0.0008 & 0.0024 & $0.9968 *$ \\
\hline V15 & 0.0367 & 0.1538 & $0.8095^{*}$ & $\mathrm{~V} 40$ & 0.0006 & $0.9991 *$ & 0.0003 \\
\hline V16 & 0.0004 & 0.0012 & $0.9984 *$ & V41 & 0.0610 & $0.8235^{*}$ & 0.1155 \\
\hline V17 & $0.9962 *$ & 0.0032 & 0.0005 & $\mathrm{~V} 42$ & $0.9966^{*}$ & 0.0029 & 0.0005 \\
\hline V18 & 0.0079 & $0.9863 *$ & 0.0058 & $\mathrm{~V} 43$ & $0.9936^{*}$ & 0.0054 & 0.0010 \\
\hline V19 & 0.0298 & 0.0695 & $0.9006^{*}$ & $\mathrm{~V} 44$ & 0.0001 & 0.0003 & $0.9996 *$ \\
\hline V20 & 0.0122 & 0.0311 & $0.9568^{*}$ & V45 & $0.9653^{*}$ & 0.0285 & 0.0062 \\
\hline V21 & 0.0779 & $0.4867 *$ & 0.4353 & V46 & 0.1354 & $0.8396^{*}$ & 0.0250 \\
\hline V22 & 0.0374 & 0.0845 & $0.8780^{*}$ & V47 & $0.8857^{*}$ & 0.1016 & 0.0126 \\
\hline $\mathrm{V} 23$ & 0.0010 & 0.0031 & $0.9959^{*}$ & V48 & $0.9846^{*}$ & 0.0128 & 0.0026 \\
\hline V24 & 0.0655 & 0.3411 & $0.5934^{*}$ & V49 & $0.9997^{*}$ & 0.0003 & 0.0001 \\
\hline V25 & 0.1010 & $0.8777^{*}$ & 0.0213 & V50 & 0.0490 & 0.2228 & $0.7281 *$ \\
\hline
\end{tabular}

e-vendors in a global B2C e-commerce business environment. The IAM enables structural data collection and identification of evaluation factors for e-vendors, which can then be classified into the VIP, PV and SV categories by the VVM. Attractive collaboration packages can be formulated with e-vendors in accordance with the corresponding classifications indicated by the VRMM. The e-vendors will have a clearer understanding of their own positions within the B2C e-commerce context and should be better able to facilitate their business development. The VRMM also facilitates systematic development of effective eVRM strategies, and e-vendors can be encouraged to actively interact with platforms and continue to do so. In order to evaluate the effectiveness of the proposed system, we conducted (i) an analysis of the selection of the fuzziness parameter and (ii) a comparative analysis with other clustering techniques.

\subsection{Selection of the Fuzziness Parameter}

In the VCM, fuzzy c-means clustering is applied to group vendors into different classifications, where a weighting parameter is set as 2 based on the routine practice. However, the effect and effectiveness 


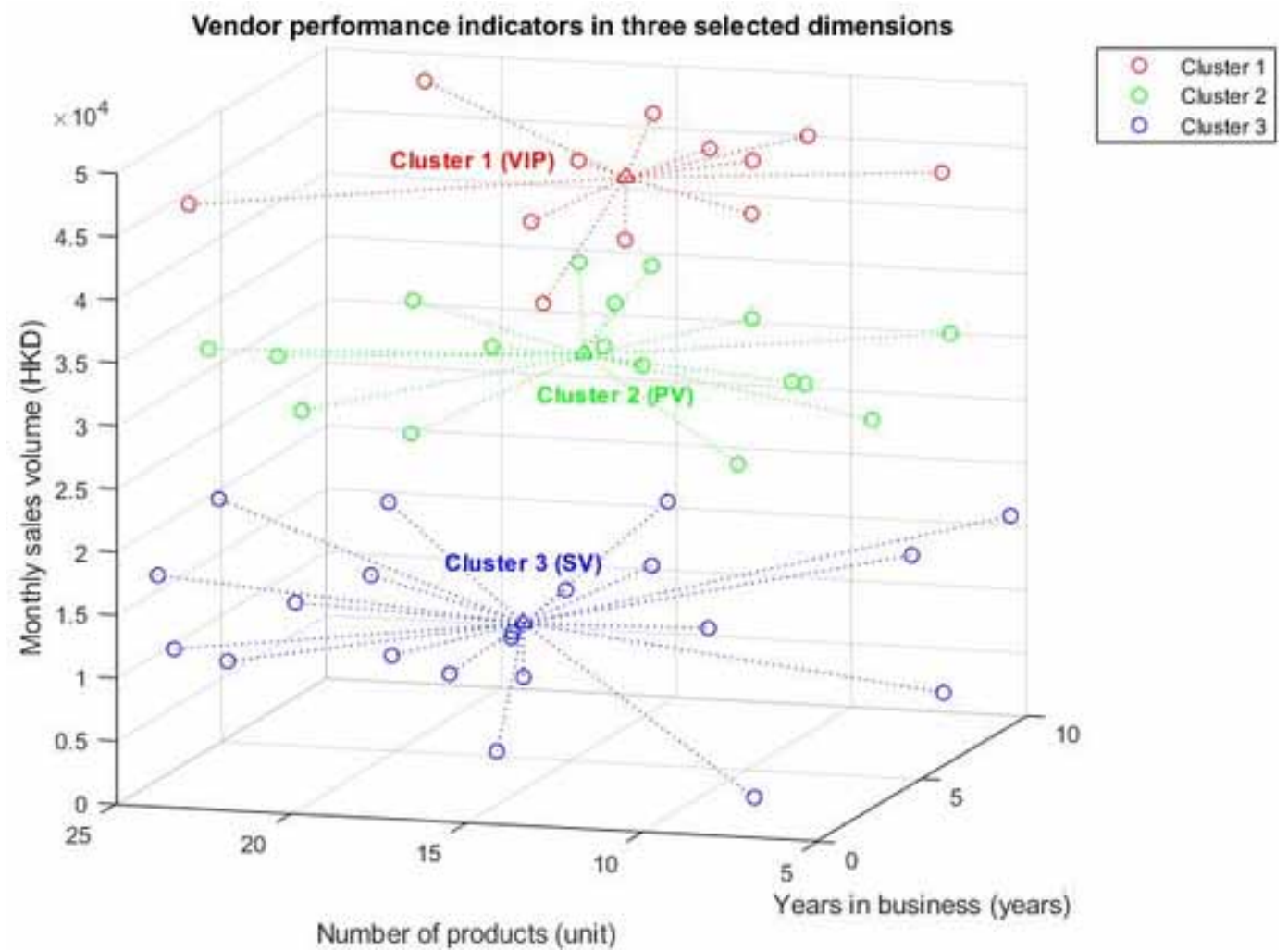

of using the fuzziness parameter $\left(m^{\prime}=2\right)$ needed to be examined in this case study. Another two fuzziness parameters (i.e., $\mathrm{m}^{\prime}=4, \mathrm{~m}^{\prime}=6$ and $\mathrm{m}^{\prime}=8$ ) were considered when evaluating the FCM process. In the analysis, thirty sets of vendor data were used to measure root-mean-squared error (RMSE) and average absolute error (ABE) between the evaluated and the supervised fuzzy partition matrix. The VCM module was applied to the thirty sets of vendor data to obtain thirty resultant fuzzy partition matrices. As shown in Table 7, it was found that the RMSE and ABE increased when using the increasing value of the fuzziness parameter ( $m^{\prime}$ ') and where the RMSE and ABE were the lowest, namely 0.0632 and 0.0463 , respectively, when $\mathrm{m}^{\prime}=2$. Compared with other scenarios ( $\mathrm{m}$ ' $=4, \mathrm{~m}^{\prime}=6$ and $\mathrm{m}^{\prime}=8$ ), the RMSE values increased by $452 \%, 563 \%$ and $563 \%$, respectively, while the $\mathrm{ABE}$ values increased by $526 \%, 733 \%$ and $735 \%$, respectively. These results reveal that selection of the fuzziness parameter in vendor data clustering follows the routine practice, which should be less than 2.6 (Yu et al., 2004). The FCM process using m' $=2$ had minimal errors and an appropriate computational load.

\subsection{Comparative Analysis With Other Clustering Techniques}

Apart from examining the parameters used in FCM, the effectiveness of adopting FCM needed to be investigated by conducting a comparative analysis with other clustering techniques, in order to evaluate the number of misclassifications and efficiency of the clustering algorithms. This section shows how k-means clustering and k-medoids clustering were used to evaluate and investigate differences in the FCM adopted in the AVRMS. These are common and well-known clustering techniques, where the difference between k-means and k-medoids clustering is that the cluster centres are updated by using the mean of measurements in the subset and using a member of the subset, 


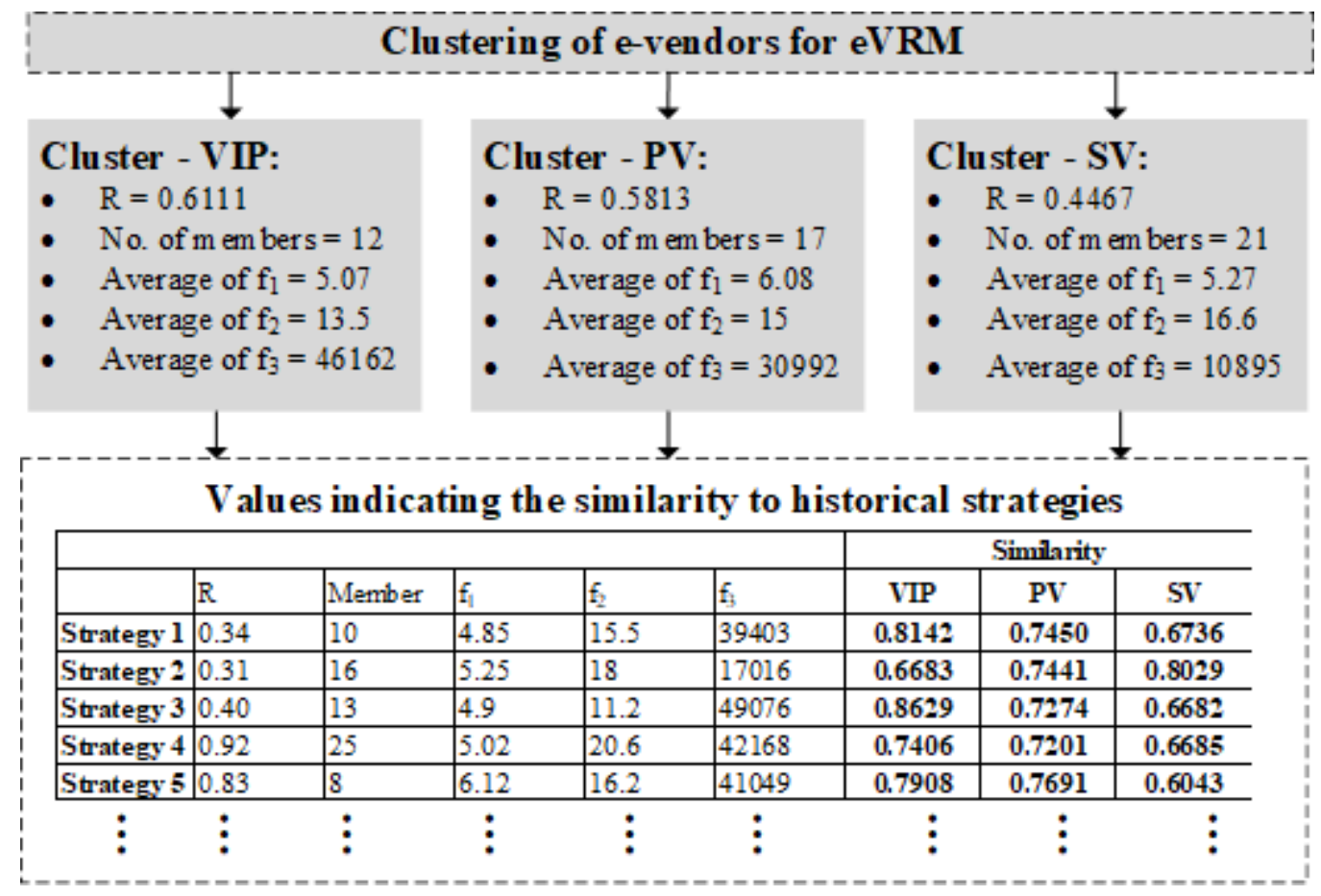

Table 6. eVRM strategies based on vendor segments

\begin{tabular}{|c|c|c|c|c|}
\hline Vendor segments & Transaction offer & $\begin{array}{c}\text { Platform } \\
\text { functionalities }\end{array}$ & Logistics services & $\begin{array}{l}\text { Customer service } \\
\text { (CS) support }\end{array}$ \\
\hline $\begin{array}{l}\text { Very Important Person } \\
\text { (VIP) }\end{array}$ & $\begin{array}{l}\text { - Slotting fee: No } \\
\text { - Transaction } \\
\text { commission: } 1 \%\end{array}$ & $\begin{array}{c}\text { - Basic e-shop } \\
\text { functions } \\
\text { - Inventory } \\
\text { management system } \\
\text { - Online chatroom } \\
\text { - Full payment } \\
\text { gateways }\end{array}$ & $\begin{array}{l}\text { - Routine shipment } \\
\text { - Express services } \\
\text { - } \$ 50 \mathrm{k} \text { credit }\end{array}$ & $\begin{array}{c}\text { - CS hotline } \\
\text { - CS email } \\
\text { - Online chatroom } \\
\text { - Dedicated } \\
\text { emergency team } \\
(24 / 7)\end{array}$ \\
\hline Premium Vendor (PV) & $\begin{array}{l}\text { - Slotting fee: } \$ 10 / \\
\text { SKU/month } \\
\text { - Transaction } \\
\text { commission: } 5 \%\end{array}$ & $\begin{array}{c}\text { - Basic e-shop } \\
\text { functions } \\
\text { - Inventory } \\
\text { management system }\end{array}$ & $\begin{array}{l}\text { - Routine shipment } \\
\text { - Express services } \\
\text { - } \$ 10 \mathrm{k} \text { credit }\end{array}$ & $\begin{array}{c}\text { - CS hotline } \\
\bullet \text { CS email } \\
\text { - Online chatroom }\end{array}$ \\
\hline Standard Vendor (SV) & $\begin{array}{l}\text { - Slotting fee: } \$ 20 / \\
\text { SKU/month } \\
\text { - Transaction } \\
\text { commission: } 8 \%\end{array}$ & $\begin{array}{l}\text { - Basic e-shop } \\
\text { functions }\end{array}$ & $\begin{array}{l}\text { - Routine shipment } \\
\text { - Cash on delivery }\end{array}$ & $\begin{array}{l}\text { - CS hotline } \\
\text { - CS email }\end{array}$ \\
\hline
\end{tabular}

respectively. FCM, k-means and k-medoids clustering are three promising clustering algorithms used to classify data points into a specific number of centroids within a multidimensional space. Comparison of the above three clustering algorithms can test the accuracy of the entire vendorevaluation clustering process in a fair manner. In order to assess the effectiveness of FCM, 20 sets of vendor evaluation matrices (containing data on 50 vendors) were used and compared with actual 
Table 7. Comparative analysis of fuzziness parameter in FCM

\begin{tabular}{|c|c|c|c|c|}
\hline & \multicolumn{4}{|c|}{ Fuzziness Parameter } \\
\hline & $\mathbf{m}^{\prime}=\mathbf{2}$ & $m^{\prime}=4$ & $m^{\prime}=6$ & $\mathrm{~m}^{\prime}=8$ \\
\hline Average iteration & 9.8 & 29.6 & 11.2 & 9.5 \\
\hline RMSE & 0.0632 & 0.3487 & 0.4187 & 0.4193 \\
\hline $\mathrm{ABE}$ & 0.0463 & 0.2899 & 0.3858 & 0.3864 \\
\hline
\end{tabular}

clustering results obtained by an e-commerce expert. The evaluation was conducted in a computer environment with Intel i7-6770HQ CPU and 32GB RAM specifications, and Windows 10 (64 bits). Figure 8 shows misclassification results among the three captioned clustering techniques, where the average number of misclassifications with FCM, k-means clustering and k-medoids clustering was found to be 3.90, 4.95 and 4.1 data points, respectively. The misclassification rate was calculated by dividing the number of misclassified vendors by the total number of vendors, as the 20 sets of vendor evaluation data had the corresponding desired classifications. By computing relevance scores for the clustered vendors using FCM, the correctness of vendor labelling could be examined. In terms of the percentage of misclassifications, the number of misclassifications with FCM was found to be lower than with k-means and k-medoids clustering (26.9\% and 5.1\%, respectively). This implied that the FCM approach is a suitable and effective approach for handling vendor clustering problems. The time taken by clustering algorithms was also examined to measure their efficiency. Figure 9 shows a comparison of the execution time for the three captioned clustering algorithms. It was found that the results from k-means and k-medoids clustering had higher variations with standard deviations of 0.00743 and 0.00649 , respectively, while standard deviation using FCM was 0.00456 , decreasing by $38.7 \%$ and $29.8 \%$, respectively. However, the execution time with FCM for the 20 sample datasets was generally higher than k-means and k-medoids clustering, with $25.8 \%$ and $17.0 \%$, respectively. It was concluded that the percentage change in execution time was higher with the FCM approach than with other methods, but in terms of absolute values, the difference in execution time was negligible. In addition, FCM obtained more accurate clustering results compared to other clustering algorithms used in this vendor clustering problem. Selection of FCM for vendor clustering is, therefore, deemed to be appropriate and applicable.

\subsection{Industrial and Managerial Implications}

Thanks to the AVRMS, the entire process of managing large numbers of e-vendors in global e-commerce can be conducted in a systematic manner. For industrial practitioners, the proposed system can be beneficial for evaluating e-vendors and formulating appropriate management strategies in order to maintain the proximity of e-vendors. With extensive networks of global e-commerce businesses, the success of B2C business not only depends on the benefits afforded to loyal customers but also on creation of trusting, reliable and effective relationships with e-vendors. In terms of the overall ecosystem of global B2C e-commerce, vendor relationship management has received relatively little attention in comparison with actual platforms and customer management. Effective eVRM can guide e-vendors and B2C e-commerce platforms towards improving together in terms of the quality and quantity of products and services supplied. With e-commerce platforms in particular, key e-vendors can be identified effectively through use of the proposed system, while a win-win situation between vendors and platforms can be achieved through offering and executing the VRM strategies. By implementing the proposed systematic AVRMS approach, effective strategies can be generated consistently when the same set of vendor data is extracted and inputted. This is essential for standardizing the entire eVRM process in global B2C e-commerce businesses. Customers, vendors and platforms in global B2C e-commerce networks can, therefore, be managed together effectively, as 
Figure 8. Evaluation of misclassifications among fuzzy c-means, k-means and k-medoids clustering

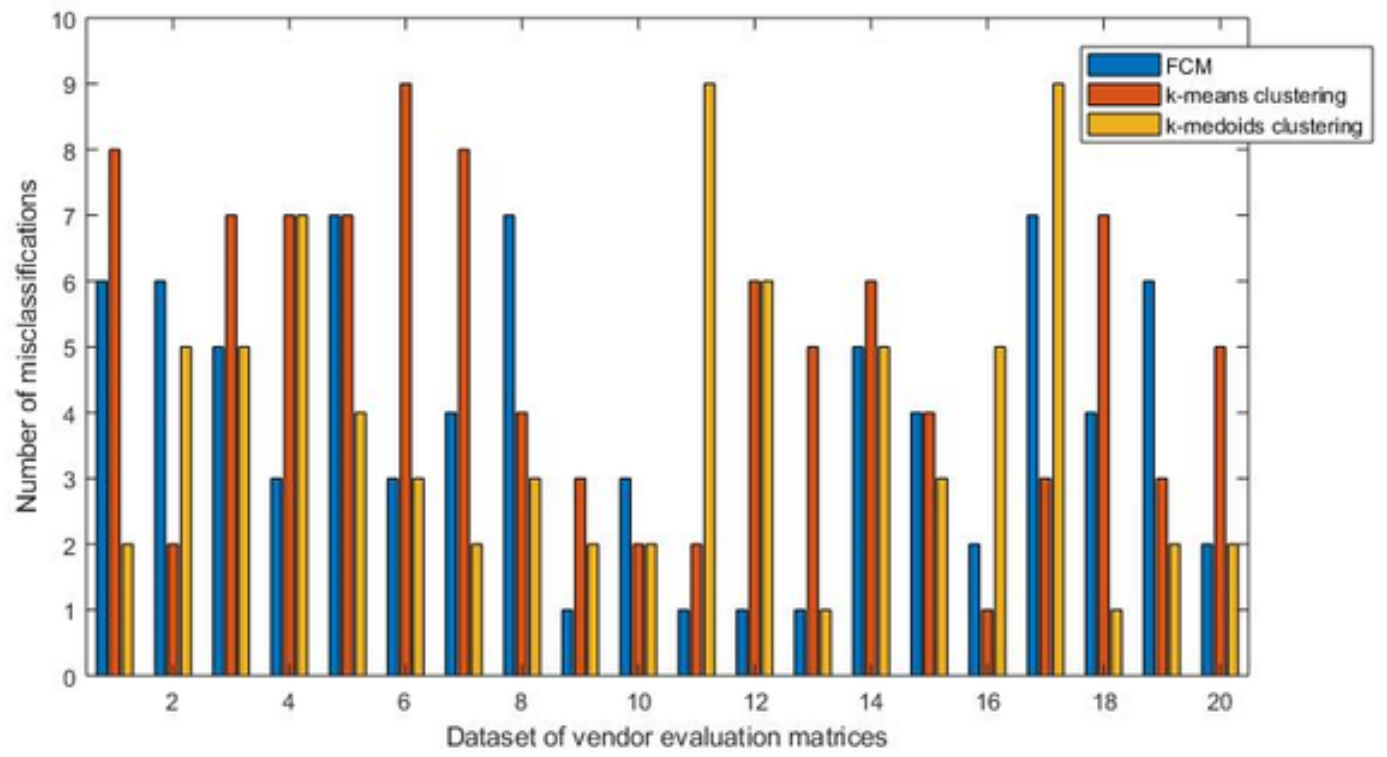

Figure 9. Comparison of execution time among fuzzy c-means, k-means and k-medoids clustering

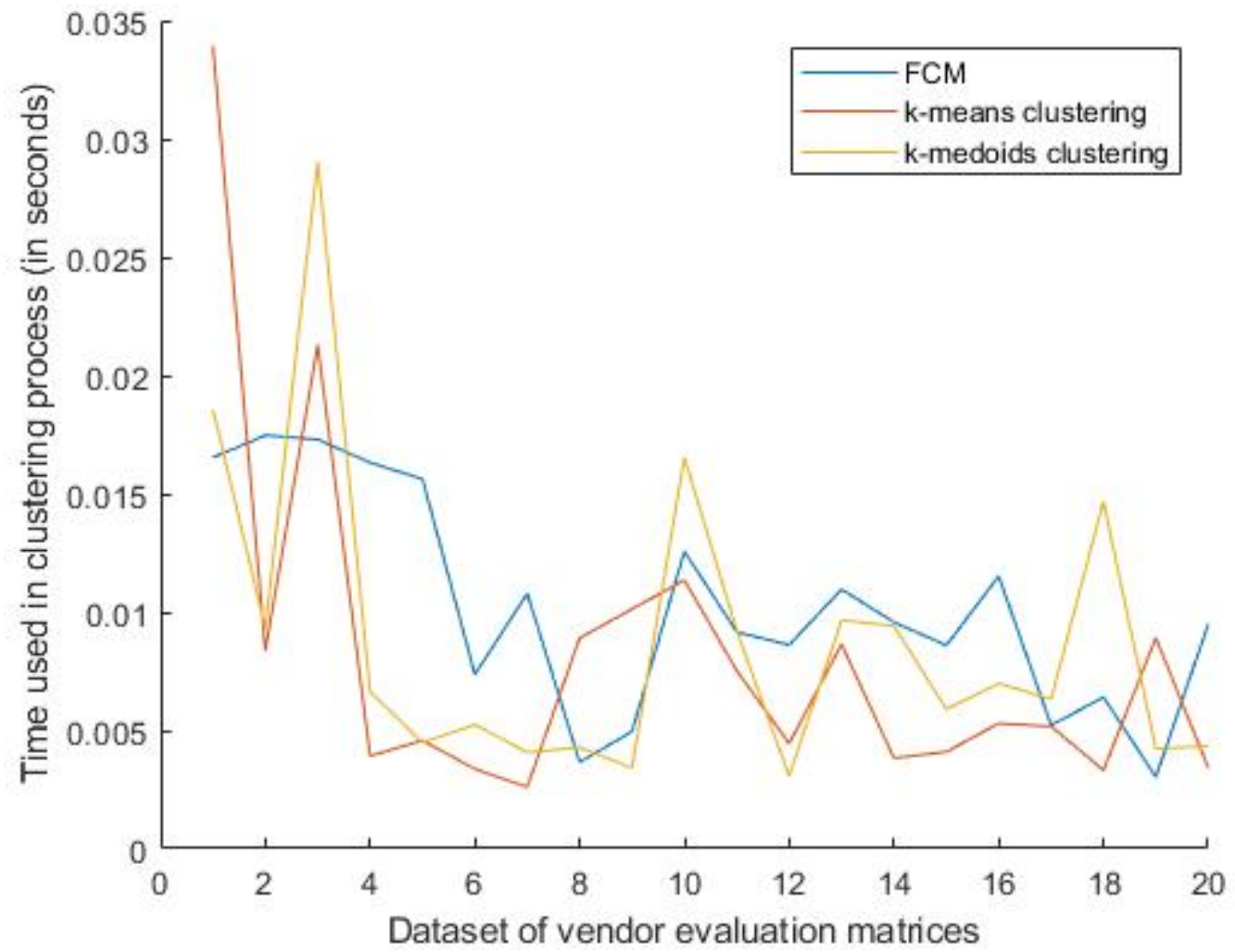


a whole, in order to develop mutual trust and beneficial relationships. By offering vendors attractive collaboration packages, e-vendors and e-commerce platforms can grow together, maintaining vendor loyalty and ensuring high-quality products and services, which will, in turn, attract more customers and help companies fight for a larger market share in the e-commerce industry. Thus, platforms can work closely with highly valued, loyal e-vendors in order to explore the market and secure higher levels of sales and profit, and ensure good quality for e-businesses.

\section{CONCLUSION}

Recent studies of eVRM have been motivated by two features of global e-commerce. Firstly, rapid growth of e-commerce (including B2C, B2B, C2C and C2B business modes) generates a great deal of data related to e-commerce transactions and activities. Data analytics, data mining and artificial intelligence techniques can be applied to dig out hidden business information and to create new business intelligence to support decision-making processes. Secondly, to improve the competitiveness of e-commerce businesses, most platforms have focused on customer perspectives and have thus formulated customer-oriented business strategies aimed at establishing loyal and active customers. However, effective vendor management in global e-commerce is essential for creating sustainable and resilient e-commerce ecosystems that provide high-quality products and services, and align with platforms' vision and mission. A positive environment for vendor and customer activities on e-commerce platforms can be promoted.

In view of the above phenomena, the adaptive e-vendor relationship-management system (AVRMS) proposed in this paper makes two key contributions. Firstly, this study focuses on a rather neglected but essential element of global e-commerce, namely e-vendor relationship management. E-vendors should be identified, attracted, retained and developed in an effective and systematic manner. Mutual trust and beneficial relationships between e-vendors and e-commerce platforms can thus be established to drive the development of global e-commerce. Secondly, our study shows that in the field of eVRM, a fuzzy c-means clustering approach can be adopted to group e-vendors into different clusters for category assignment and evaluation in terms of their relevance scores. This information can then be used to customize appropriate VRM strategies for e-vendors. The proposed method provides greater flexibility when investigating the degree of belongingness to categories, thus enabling vendor performance and activity trends to be measured. This study has two limitations. Firstly, in this case study, only fifty vendors were used to illustrate the proposed system and VRM strategy establishment, and the dimensions of the vendor evaluation factors were fixed. Secondly, the proposed system for VRM focuses on B2C e-commerce only and not other modes of e-commerce. In the future, additional case studies using the proposed methodology could be conducted, covering other modes of e-commerce such as $\mathrm{B} 2 \mathrm{~B}$ and $\mathrm{C} 2 \mathrm{~B}$, in order to promote effective VRM in global e-businesses. Other evaluation factors in e-vendor relationship management could also be considered. Future work could focus on developing the model, with additional evaluation of the number of clusters in the field of eVRM, in order to cater for various requirements in realistic business contexts.

\section{ACKNOWLEDGMENT}

This study was partially supported by a matching grant under UGC's Research Matching Grant Scheme (second cycle). Our gratitude is extended to the Big Data Intelligence Centre at The Hang Seng University of Hong Kong, which supported the research. The authors would also like to thank the handling editor and reviewers for their valuable comments and suggestions, which have improved the quality of this paper. 


\section{REFERENCES}

Arora, J., Khatter, K., \& Tushir, M. (2019). Fuzzy c-means clustering strategies: A review of distance measures. In Software Engineering (pp. 153-162). Springer. doi:10.1007/978-981-10-8848-3_15

Balcan, M. F. F., Ehrlich, S., \& Liang, Y. (2013). Distributed k-means and k-median Clustering on General Topologies. In Advances in Neural Information Processing Systems (pp. 1995-2003). Academic Press.

Bezdek, J. C., Ehrlich, R., \& Full, W. (1984). FCM: The fuzzy c-means clustering algorithm. Computers \& Geosciences, 10(2-3), 191-203. doi:10.1016/0098-3004(84)90020-7

Bullen, C. V., LeFave, R., \& Selig, G. J. (2017). Client-Vendor Relationship Management in Global Sourcing. In Global Sourcing Of Services (pp. 301-333). Strategies, Issues And Challenges. doi:10.1142/9789813109315_0008

Cai, L., He, X., Dai, Y., \& Zhu, K. (2018, September). Research on B2B2C E-commerce Website Design Based on User Experience. Journal of Physics: Conference Series, 1087(6), 062043. doi:10.1088/1742-6596/1087/6/062043

Campbell, D. E. (2019). A relational build-up model of consumer intention to self-disclose personal information in e-commerce B2C relationships. AIS Transactions on Human-Computer Interaction, 11(1), 33-53. doi: $10.17705 / 1$ thci.00112

Chang, B., Chang, C. W., \& Wu, C. H. (2011). Fuzzy DEMATEL method for developing supplier selection criteria. Expert Systems with Applications, 38(3), 1850-1858. doi:10.1016/j.eswa.2010.07.114

Chaturvedi, A., Green, P. E., \& Caroll, J. D. (2001). K-modes clustering. Journal of Classification, 18(1), 35-55. doi:10.1007/s00357-001-0004-3

Cleary, S., \& McLarney, C. (2019). Organizational Benefits of an Effective Vendor Management Strategy. IUP Journal of Supply Chain Management, 16(4).

Durai, T., \& Stella, G. (2017). A Study on The Effect of Electronic Customer Relationship Management (ecrm) On Customer Satisfaction Of E-Commerce Websites. Journal of Marketing Strategy, 5(3), 332-339.

En-Naimi, E. M., \& Zouhair, A. (2016). Intelligent dynamic case-based reasoning using multi-agents system in adaptive e-service, e-commerce and e-learning systems. International Journal of Knowledge and Learning, $11(1), 42-57$.

Espinosa, J. A., Davis, D., Stock, J., \& Monahan, L. (2019). Exploring the processing of product returns from a complex adaptive system perspective. International Journal of Logistics Management, 30(3), 699-722. doi:10.1108/IJLM-08-2018-0216

Govindan, K., Rajendran, S., Sarkis, J., \& Murugesan, P. (2015). Multi criteria decision making approaches for green supplier evaluation and selection: A literature review. Journal of Cleaner Production, 98, 66-83. doi:10.1016/j.jclepro.2013.06.046

Gu, C., \& Tian, X. (2017). A Strategy of Re-negotiation with Case-Based Reasoning. Boletín Técnico, 55(7), $247-252$.

Hamidi, H., \& Moradi, S. (2017). Analysis of consideration of security parameters by vendors on trust and customer satisfaction in e-commerce. Journal of Global Information Management, 25(4), 32-45. doi:10.4018/ JGIM.2017100103

Hong, I. B. (2018). Building Initial Trust in an Intermediary in B2C Online Marketplaces: The Korean Evidence From Interpark. com. Journal of Global Information Management, 26(2), 27-47. doi:10.4018/JGIM.2018040102

Jain, A. K. (2010). Data clustering: 50 years beyond K-means. Pattern Recognition Letters, 31(8), $651-666$. doi:10.1016/j.patrec.2009.09.011

Keskin, G. A. (2015). Using integrated fuzzy DEMATEL and fuzzy C: Means algorithm for supplier evaluation and selection. International Journal of Production Research, 53(12), 3586-3602. doi:10.1080/00207543.201 4.980461

Kim, Y., \& Peterson, R. A. (2017). A Meta-analysis of Online Trust Relationships in E-commerce. Journal of Interactive Marketing, 38, 44-54. doi:10.1016/j.intmar.2017.01.001 
Lee, C. K. H. (2019). A knowledge-based product development system in the chemical industry. Journal of Intelligent Manufacturing, 30(3), 1371-1386. doi:10.1007/s10845-017-1331-5

Liu, Y., Lu, J., Mao, F., \& Tong, K. (2019). The product quality risk assessment of e-commerce by machine learning algorithm on spark in big data environment. Journal of Intelligent \& Fuzzy Systems, (Preprint), 1-11.

Majumder, A., Guchhait, R., \& Sarkar, B. (2017). Manufacturing quality improvement and setup cost reduction in a vendor-buyer supply chain model. European Journal of Industrial Engineering, 11(5), 588-612. doi:10.1504/ EJIE.2017.087678

Maxwell, S., \& Khan, A. M. (2018). Electronic customer relationship management (E-CRM): A study of its role, influence \& benefitsto e-commerce. Management Dynamics, 18(1).

Mazzarol, T. (2015). SMEs engagement with e-commerce, e-business and e-marketing. Small Enterprise Research, 22(1), 79-90. doi:10.1080/13215906.2015.1018400

Montazer, G. A., Saremi, H. Q., \& Ramezani, M. (2009). Design a new mixed expert decision aiding system using fuzzy ELECTRE III method for vendor selection. Expert Systems with Applications, 36(8), 10837-10847. doi:10.1016/j.eswa.2009.01.019

Okwu, M. O., \& Tartibu, L. K. (2020). Sustainable supplier selection in the retail industry: A TOPSIS-and ANFIS-based evaluating methodology. International Journal of Engineering Business Management, 12. Advance online publication. doi:10.1177/1847979019899542

Omondi, A. O., \& Mbugua, A. W. (2017). An Application of association rule learning in recommender systems for e-Commerce and its effect on marketing. Academic Press.

Payan, J. M., Hair, J., Svensson, G., Andersson, S., \& Awuah, G. (2016). Modeling Antecedents in TrustCommitment Vendor Relationships. In Rediscovering the Essentiality of Marketing (pp. 321-321). Springer. doi:10.1007/978-3-319-29877-1_65

Prashar, S., Tata, S. V., Parsad, C., Banerjee, A., Sahakari, N., \& Chatterjee, S. (2019). Clustering E-Shoppers on the Basis of Shopping Values and Web Characteristics. Journal of Global Information Management, 27(2), 24-38. doi:10.4018/JGIM.2019040102

Rouibah, K., Lowry, P. B., \& Almutairi, L. (2015). Dimensions of business-to-consumer (B2C) systems success in Kuwait: Testing a modified DeLone and McLean IS success model in an e-commerce context. Journal of Global Information Management, 23(3), 41-71. doi:10.4018/JGIM.2015070103

Saunila, M., Ukko, J., Sore, S., Rantala, T., \& Nasiri, M. (2019, October). Managing buyer-supplier relationships in e-commerce projects: Implications for relationship value. Supply Chain Forum International Journal (Toronto, Ont.), 20(4), 299-309.

Sharma, R. R., Chadee, D., \& Roxas, B. (2016). Effects of knowledge management on client-vendor relationship quality: The mediating role of global mindset. Journal of Knowledge Management, 20(6), 1268-1281. doi:10.1108/ JKM-03-2016-0099

Song, Q., \& Shepperd, M. (2006). Mining web browsing patterns for E-commerce. Computers in Industry, 57(7), 622-630. doi:10.1016/j.compind.2005.11.006

Tang, V., Siu, P. K., Choy, K. L., Ho, G. T. S., Lam, H. Y., \& Tsang, Y. P. (2018). A web mining-based case adaptation model for quality assurance of pharmaceutical warehouses. International Journal of Logistics Research and Applications, 1-24.

Vyas, A., \& Gupta, S. (2017). Challenges assessment for the e-commerce industry in India: A review (With Special Reference to Flipkart V/S Snapdeal). Journal of Global Information Management, 25(4), 16-31. doi:10.4018/JGIM.2017100102

Wang, S., Cavusoglu, H., \& Deng, Z. (2016). Early mover advantage in e-commerce platforms with low entry barriers: The role of customer relationship management capabilities. Information \& Management, 53(2), $197-206$. doi:10.1016/j.im.2015.09.011

Wang, W. T., Wang, Y. S., \& Liu, E. R. (2016). The stickiness intention of group-buying websites: The integration of the commitment-trust theory and e-commerce success model. Information \& Management, 53(5), 625-642. doi:10.1016/j.im.2016.01.006 
Wang, Y. J. (2010). A clustering method based on fuzzy equivalence relation for customer relationship management. Expert Systems with Applications, 37(9), 6421-6428. doi:10.1016/j.eswa.2010.02.076

Yu, J., Cheng, Q., \& Huang, H. (2004). Analysis of the weighting exponent in the FCM. IEEE Transactions on Systems, Man, and Cybernetics. Part B, Cybernetics, 34(1), 634-639. doi:10.1109/TSMCB.2003.810951 PMID:15369100

Zhang, Y., Fang, Y., Wei, K. K., Ramsey, E., McCole, P., \& Chen, H. (2011). Repurchase intention in B2C e-commerce-A relationship quality perspective. Information \& Management, 48(6), 192-200. doi:10.1016/j. im.2011.05.003 


\section{APPENDIX}

Table 8. Data for formulation of vendor evaluation matrix

\begin{tabular}{|c|c|c|c|c|c|c|c|}
\hline & Years in business & $\begin{array}{l}\text { SKUs of } \\
\text { products }\end{array}$ & $\begin{array}{c}\text { Monthly } \\
\text { sales volume }\end{array}$ & & $\begin{array}{l}\text { Years in } \\
\text { business }\end{array}$ & $\begin{array}{l}\text { SKUs of } \\
\text { products }\end{array}$ & $\begin{array}{c}\text { Monthly } \\
\text { sales volume }\end{array}$ \\
\hline V1 & 8.70 & 17 & 35443.5 & V26 & 6.90 & 11 & 33699.6 \\
\hline $\mathbf{V} 2$ & 8.80 & 11 & 26766.9 & V27 & 4.20 & 18 & 7173.9 \\
\hline V3 & 5.40 & 14 & 35973.4 & V28 & 9.50 & 8 & 12793.8 \\
\hline V4 & 7.20 & 14 & 49218.3 & V29 & 1.80 & 24 & 45897.6 \\
\hline V5 & 8.60 & 12 & 44379.3 & V30 & 8.80 & 23 & 9673.9 \\
\hline V6 & 2.70 & 15 & 8870.4 & V31 & 3.80 & 12 & 17057.1 \\
\hline V7 & 6.40 & 16 & 11950.8 & V32 & 0.30 & 13 & 41181.5 \\
\hline V8 & 8.00 & 6 & 32171.3 & V33 & 7.20 & 18 & 7469.7 \\
\hline V9 & 4.40 & 25 & 31677.6 & V34 & 6.30 & 21 & 18259.9 \\
\hline V10 & 5.70 & 20 & 24425.6 & V35 & 1.20 & 15 & 36571.2 \\
\hline V11 & 9.80 & 23 & 2306.9 & V36 & 7.70 & 25 & 27840 \\
\hline V12 & 2.00 & 25 & 16146.8 & V37 & 4.90 & 11 & 49161.4 \\
\hline V13 & 1.70 & 11 & 35138.1 & V38 & 6.50 & 12 & 9392.1 \\
\hline V14 & 8.20 & 16 & 29428.1 & V39 & 1.10 & 24 & 11348.5 \\
\hline V15 & 9.20 & 5 & 16661.5 & V40 & 0.50 & 20 & 31429.6 \\
\hline V16 & 5.20 & 23 & 11082.4 & V41 & 7.60 & 8 & 25431.6 \\
\hline V17 & 7.60 & 6 & 45327.8 & $\mathrm{~V} 42$ & 7.00 & 16 & 45368.6 \\
\hline V18 & 6.10 & 9 & 29588.9 & $\mathrm{~V} 43$ & 7.90 & 10 & 47336.1 \\
\hline V19 & 3.10 & 16 & 2424 & V44 & 3.80 & 16 & 10745.6 \\
\hline V20 & 6.00 & 5 & 5836.4 & V45 & 0.20 & 7 & 49266.1 \\
\hline V21 & 7.90 & 12 & 21013.7 & V46 & 8.80 & 15 & 35386.3 \\
\hline V22 & 2.00 & 8 & 1078 & V47 & 4.20 & 13 & 42326.7 \\
\hline $\mathrm{V} 23$ & 0.30 & 22 & 11477.5 & V48 & 9.70 & 22 & 48083 \\
\hline V24 & 4.90 & 25 & 19302.4 & V49 & 1.40 & 14 & 46402.1 \\
\hline V25 & 5.80 & 20 & 34886.1 & V50 & 7.90 & 14 & 17749.8 \\
\hline
\end{tabular}


H. Y. Lam received her BSc (Hons) Logistics Engineering and Management and PhD in Industrial and Systems Engineering from the Hong Kong Polytechnic University in 2008 and 2014 respectively. She is currently a Lecturer in The Hang Seng University of Hong Kong. Her current research areas cover supply chain management, warehouse and logistics management, decision support system and artificial intelligence applications.

Y. P. Tsang is a research student at the Department of Industrial and Systems Engineering of the Hong Kong Polytechnic University. He is currently pursuing a Ph.D. degree. He received his Bachelor's degree in Logistics Engineering and Management from the Hong Kong Polytechnic University in 2015. His current research areas cover loT applications, blockchain technology, artificial intelligence, cold chain management, and e-commerce services and systems.

C. $H$. Wu received the BEng and PhD degrees in Industrial and Systems Engineering from the Hong Kong Polytechnic University (PolyU) in 2006 and 2011 respectively. He is currently an Assistant Professor of the Department of Supply Chain and Information Management at The Hang Seng University of Hong Kong. He also holds a six-sigma black belt certification from the Hong Kong Society of Quality, and he contributes regularly to research papers in the areas of IloT, Industry 4.0 and healthcare technology. His project work and research outcomes have been presented in 10+ international conferences and published in 50+ international refereed journals. As he looks to the future, Dr Wu intends to continue researching in the field of smart logistics and manufacturing.

Ching-Yuen Chan was awarded his BEng in Mechanical Engineering at Salford University (UK) in 1989, going on to received his PhD in Manufacturing Engineering in 1994. At present, he is a lecturer in the Department of Industrial and Systems Engineering, The University of Hong Kong Polytechnic, Hong Kong. His research interests are Industrial Automation, Production Monitoring, Production System Modelling and Staff Rostering. 